\title{
Still Clever After All These Years: Searching for the Homunculus in Explicitly Cued Task Switching
}

\author{
Gordon D. Logan and Darryl W. Schneider \\ Vanderbilt University
}

\author{
Claus Bundesen \\ University of Copenhagen
}

\begin{abstract}
Many researchers interpret switch costs in the explicit task-cuing procedure as reflecting endogenous task-set reconfiguration. G. D. Logan and C. Bundesen (2003) challenged this interpretation empirically and theoretically. They argued that many experiments confounded cue encoding benefits with switch costs and they showed that unconfounded switch costs could be vanishingly small. They proposed a theory in which subjects use a single task set in the explicit task-cuing procedure and switch costs reflect cue encoding benefits, not reconfiguration. S. Monsell and G. A. Mizon (2006) responded to these challenges, describing conditions under which substantial switch costs could be observed in the explicit task-cuing procedure and providing a theoretical account of performance in which reconfiguration occurred in G. D. Logan and C. Bundesen's experiments. This article is a response to S. Monsell and G. A. Mizon's challenge that highlights empirical problems with their evidence and reports an experiment that challenges critical assumptions of their theoretical account.
\end{abstract}

Keywords: task switching, endogenous control, sequential comparison, cue encoding, priming

Introduced by Jersild in 1927 and largely ignored for many years, task-switching procedures have become popular in recent years. Seminal papers by Allport, Styles, and Hsieh (1994) and Rogers and Monsell (1995) pointed out the relevance of task switching to the study of executive control of cognitive processes, which itself has become a popular topic (Logan, 1985; Miller \& Cohen, 2001; Monsell, 1996). Jersild's (1927) finding of switch costs-slower reaction times (RTs) and lower accuracy when switching than repeating tasks - has been replicated many times with various procedures (for reviews, see Logan, 2003; Monsell, 2003). The allure of task-switching procedures is that switch costs may provide measures of the time it takes executive control processes to reconfigure the cognitive system.

The explicit task-cuing procedure has been particularly alluring. It involves presenting a cue that indicates which task to perform on a target that appears after a controlled interval (stimulus onset asynchrony, or SOA) and has the potential to isolate reconfiguration processes from subordinate task processes. Cues and targets often appear in random order, and trials are sorted post hoc into repetitions and alternations (depending on whether the task re-

Gordon D. Logan and Darryl W. Schneider, Department of Psychology, Vanderbilt University; Claus Bundesen, Department of Psychology, University of Copenhagen, Copenhagen, Denmark.

This research was supported by National Science Foundation Grant BCS 0446806. We are grateful to Julie Delheimer for testing the subjects; Stephen Monsell for providing means of mean and median reaction times from all of the experiments in Monsell and Mizon (2006); and Ronald Hübner, Nachshon Meiran, and Sander Nieuwenhuis for comments on previous drafts of this article.

Correspondence concerning this article should be addressed to Gordon D. Logan, Department of Psychology, Vanderbilt University, Nashville, TN 37203, e-mail: gordon.logan@ vanderbilt.edu, or to Darryl Schneider at darryl.schneider@vanderbilt.edu or Claus Bundesen at claus.bundesen@ psy.ku.dk peats or alternates across trials), with switch costs calculated by subtracting repetitions from alternations. Switch costs reliably decrease as SOA increases (e.g., Meiran, 1996; but see Altmann, 2004), which suggests that reconfiguration begins with cue onset and sometimes finishes before target onset. This reduction in switch costs with SOA is taken by many as strong evidence for endogenous reconfiguration (Meiran, 1996, 2000; Meiran, Chorev, \& Sapir, 2000; Monsell \& Mizon, 2006; Rogers \& Monsell, 1995; Rubinstein, Meyer, \& Evans, 2001).

Logan and Bundesen (2003) challenged this interpretation empirically and theoretically. They identified an important confound in most experiments with the explicit task-cuing procedure and proposed a theory of explicitly cued performance that explains switch costs as priming effects instead of endogenous reconfiguration effects (see also Arrington \& Logan, 2004a; Logan \& Bundesen, 2004; Logan \& Schneider, 2006a, 2006b; Schneider \& Logan, 2005, 2006). Monsell and Mizon (2006) responded to this challenge, reporting conditions under which switch costs do appear to reflect reconfiguration and proposing a theoretical account of Logan and Bundesen's (2003) results that involves reconfiguration instead of priming.

The purpose of the present article is to respond to Monsell and Mizon's (2006) challenge to our position. We begin by describing a common reconfiguration interpretation of switch costs. Then we review our alternative theoretical interpretation and the evidence that supports it and respond to Monsell and Mizon's critique of our theory. Then we show that our theory can account for some of Monsell and Mizon's results, which they interpreted as evidence for endogenous reconfiguration. Then we report an experiment that tests (and falsifies) a critical assumption of Monsell and Mizon's account of our data. We end with a discussion of Monsell and Mizon's "recipe" for observing endogenous reconfiguration and we propose a recipe of our own. 


\section{A Reconfiguration Interpretation of Switch Costs}

Many researchers interpret reductions in switch cost with SOA as evidence for endogenous reconfiguration (Meiran, 1996, 2000; Meiran et al., 2000; Monsell \& Mizon, 2006; Rogers \& Monsell, 1995; Rubinstein et al., 2001). In theory, performance of a task depends on a special state of preparation called a task set that allows the cognitive system to achieve task goals, and reconfiguration is an endogenous process that achieves this state of preparation. Although not always stated explicitly, reconfiguration theories assume that performance in the explicit task-cuing procedure involves a sequential task comparison strategy: If the current cue indicates the same task as the previous cue, the task set from the previous trial is appropriate for the current trial, so no reconfiguration is required. If the current cue indicates a different task than the previous cue, the task set must be reconfigured (Logan \& Bundesen, 2003, Models 1 and $2+1$; Monsell \& Mizon, 2006). Reconfiguration is assumed to take time, which accounts for switch costs. This interpretation assumes that subjects compare the current task with the previous one and use the result of that comparison to decide whether to reconfigure the task set. We assess the plausibility of this assumption in the experiment we report below.

\section{Logan and Bundesen's (2003) Challenge to the Reconfiguration Interpretation}

\section{Empirical Issues}

Logan and Bundesen (2003) challenged this interpretation empirically and theoretically. Empirically, they noticed a confound that was present in all previous experiments with the explicit task-cuing procedure, which Mayr and Kliegl (2003) also noticed: The experiments used only one cue for each task (e.g., High-Low cued magnitude judgments of digits and Odd-Even cued parity judgments of digits), so cue repetition was confounded with task repetition. Whenever the task repeated, the cue repeated; whenever the task switched, the cue switched. Thus, switch costs could simply reflect cue repetition benefits instead of (or as well as) endogenous reconfiguration. To address this confound, Logan and Bundesen (2003) and Mayr and Kliegl (2003) presented two cues for each task (e.g., High-Low and Magnitude for magnitude judgments of digits; Odd-Even and Parity for parity judgments of digits). This procedure allows three transitions between trials: cue repetitions, in which the cue and the task repeat (e.g., High-Low $\rightarrow$ High-Low), task repetitions, in which the cue changes but the task repeats (e.g., Magnitude $\rightarrow$ High-Low), and task alternations, in which the cue and the task both change (e.g., Odd-Even $\rightarrow$ High-Low). The difference between task repetitions and cue repetitions reflects cue encoding benefits unconfounded with switch costs. The difference between task alternations and task repetitions reflects "true switch costs" unconfounded with cue encoding benefits. The traditional measure of switch cost in the explicit taskcuing procedure compares cue repetitions with task alternations, confounding cue encoding benefits with true switch costs.

Logan and Bundesen (2003) conducted two experiments with two cues per task. In each experiment, they found substantial cue encoding benefits and very small true switch costs $(35 \mathrm{~ms}$ in one experiment, $14 \mathrm{~ms}$ in the other). These results challenged the interpretation of traditional switch costs as measures of endogenous reconfiguration: If reconfiguration occurs in this procedure, its duration is vanishingly small. Monsell and Mizon (2006) addressed these results in their critique of our work, but they did not address several replications of these results (Arrington \& Logan, 2004a, 2005; Logan \& Bundesen, 2004; Logan \& Schneider, 2006b; Schneider \& Logan, 2005, 2006), though they cited the papers in their article. The results of the replications have important implications for Monsell and Mizon's conclusions, which we address below.

\section{Theoretical Issues}

Logan and Bundesen (2003) also challenged the reconfiguration interpretation of switch costs by presenting a theory of explicitly cued performance that does not involve endogenous reconfiguration. They noted that the cue and the target jointly specify the correct response on each trial. They proposed that subjects exploit this information with a compound stimulus strategy, whereby they encode the cue, encode the target, and choose the response associated with the combination. This strategy can be used on every trial, whether or not the cue repeats, so there is no need for reconfiguration. One task set can be used for every trial. Cue encoding may benefit from repetition, but there will be no true switch costs, as Logan and Bundesen observed in their Experiments 3 and 4 (i.e., there were large differences between cue repetitions and task repetitions and small differences between task repetitions and task alternations).

Subsequent articles expanded these ideas to allow for true switch costs that do not reflect reconfiguration. Arrington and Logan (2004a) suggested that subjects may retrieve responses from semantic memories acquired before the experiment as well as from episodic memories acquired during the experiment. Schneider and Logan (2005; Logan \& Schneider, 2006b) suggested that different cues assigned to the same task may prime each other associatively or semantically, so task repetitions may be faster than task alternations. Logan and Bundesen (2004) and Logan and Schneider (2006a) extended the compound stimulus strategy from meaningful word cues to arbitrary cues that are unrelated to the tasks. They proposed that subjects deal with arbitrary cues by retrieving mediators (e.g., task names), which are combined with the presented targets to form compound retrieval cues, which are then used to retrieve a response from semantic or episodic memory. Mediator retrieval may benefit from repetition, producing differences between task repetitions (where the same mediator is retrieved on successive trials) and task alternations (where different mediators are retrieved).

\section{From Theories to Models}

An important component of Logan, Bundesen, and Schneider's research program is the translation of theories into mathematical models of time-course functions (plots of RT against SOA) in the explicit task-cuing procedure that can be used to measure the durations of underlying processes. They developed several related models, some of which capture the reconfiguration view, while others capture different versions of the compound retrieval cue strategy. The main advantage of these models is that they allow precise specification of the reconfiguration view and the alterna- 
tives to it, so the approaches can be distinguished quantitatively as well as qualitatively. Most other approaches to task switching, particularly those expressing the reconfiguration view, allow only qualitative distinctions (but see Meiran, 2000).

The key idea underlying all of the models is that the time-course function reflects the cumulative distribution of cue encoding times and task-set switching times. RT will be slow if cue encoding and task-set switching have not finished by target onset, and it will be fast if cue encoding and task-set switching have finished by target onset. RT is a probability mixture of these slow and fast trials, and the mixture probability reflects the cumulative distribution of the finishing times of cue encoding and task-set switching (for details, see Logan \& Bundesen, 2003).

Model $2+1$. Logan and Bundesen (2003) proposed a general model that captured the idea that cue encoding benefits from repetition priming for cue repetitions, as well as the idea that reconfiguration is required for task alternations but not for task repetitions or cue repetitions. For cue repetitions, mean RT = $R T_{\text {Base }}+\mu_{r}$ if the cue has not been encoded, and mean $\mathrm{RT}=$ $R T_{\text {Base }}$ if the cue has been encoded, where $\mu_{r}$ is the mean cue encoding time for repeated cues and $R T_{\text {Base }}$ is the time required for processing the target, choosing a response, and responding. $\mathrm{Ob}-$ served RT is a probability mixture of these two cases:

$$
R T_{\text {Repetition }}=R T_{\text {Base }}+\mu_{r} \exp \left[-S O A / \mu_{r}\right] .
$$

The equation for task repetitions is the same as Equation 1, except that cue encoding does not benefit from repetition because the cue changes. Thus, if $\mu_{a}$ is the mean cue encoding time when the cue changes, then mean RT $=R T_{\text {Base }}+\mu_{a}$ if the cue has not been encoded, and mean RT $=R T_{\text {Base }}$ if the cue has been encoded. Observed RT is a probability mixture of these two cases:

$$
R T=R T_{\text {Base }}+\mu_{a} \exp \left[-S O A / \mu_{a}\right]
$$

For task alternations, mean $\mathrm{RT}=R T_{\text {Base }}+\mu_{a}+\mu_{s}$ if the cue has not been encoded and the task set has not been switched, where $R T_{\text {Base }}$ and $\mu_{a}$ are base RT and mean cue encoding time when the cue changes, as in Equation 2, and $\mu_{s}$ is the mean time required to switch task sets. If the cue has been encoded but the task set has not been switched, mean RT $=R T_{\text {Base }}+\mu_{s}$. If cue encoding and task-set switching are both complete, then mean $\mathrm{RT}=R T_{\text {Base }}$. The probability mixture of these three cases yields:

$$
\begin{aligned}
& R T_{\text {Alternation }}=R T_{\text {Base }}+\exp \left[-S O A / \mu_{a}\right] \cdot\left(\mu_{a}+\mu_{s}\right) \\
& +\frac{1 / \mu_{a}}{1 / \mu_{a}-1 / \mu_{s}}\left(\exp \left[-S O A / \mu_{s}\right]-\exp \left[-S O A / \mu_{a}\right]\right) \cdot \mu_{s} .
\end{aligned}
$$

Logan and Bundesen (2003) investigated two more specific models that are nested in Model $2+1$. Model 1 assumes there is task-set switching for task alternations but there is no cue encoding benefit for cue repetitions. Thus, $\mu_{r}=\mu_{a}$. This model fit their data significantly worse than Model $2+1$, indicating there were substantial cue encoding benefits. Model 2 assumes there are cue encoding benefits for cue repetitions but there is no task-set switching for task alternations. Thus, $\mu_{s}=0$. This model did not fit their data significantly worse than Model $2+1$, indicating that there is no need to postulate task-set switching in Logan and Bundesen's (2003) experiments.
Priming model. Schneider and Logan (2005) developed a priming model that unpacked parameters of Model 2 and explained them in terms of more fundamental psychological processes (i.e., similarities between cues, similarities between cues and targets, race models of cue encoding, and random-walk models of compound cue retrieval) articulated in the language of the instance theory of attention and memory (ITAM; Logan, 2002). The details of these developments are important but not directly relevant to the purposes of this article. For the present, it is sufficient to characterize their priming model in terms of cue encoding times for trials on which repetition priming occurs $\left(\mu_{r}\right)$, for trials on which associative priming occurs $\left(\mu_{a}\right)$, and for "unprimed" trials on which no priming occurs $\left(\mu_{u}\right)$. Thus, for cue repetitions,

$$
R T=R T_{\text {Base }}+\mu_{r} \exp \left[-S O A / \mu_{r}\right]
$$

for task repetitions,

$$
R T=R T_{\text {Base }}+\mu_{a} \exp \left[-S O A / \mu_{a}\right]
$$

and for task alternations

$$
R T=R T_{\text {Base }}+\mu_{u} \exp \left[-S O A / \mu_{u}\right] .
$$

Schneider and Logan (2005; also see Logan \& Schneider, 2006b) found excellent fits of Equations 4-6, deriving the parameters from other equations that represent more fundamental underlying processes. ${ }^{1}$

The priming model represents the current state of our challenge to theories that interpret switch costs in terms of endogenous reconfiguration. Our formal instantiation of reconfiguration theories has not led to better fits to the data than we obtained with our priming model. The fits of the priming model indicate that the computational processes underlying the mathematics are sufficient to account for performance, so additional endogenous reconfiguration processes do not seem necessary. At the very least, we have shown that the priming model provides a principled account of data that have been interpreted as evidence for endogenous reconfiguration.

\section{Monsell and Mizon's (2006) Critique of Our Priming Model}

Monsell and Mizon (2006) criticized our priming model of explicitly cued performance on several grounds. First, they suggested that the parsimony in our model is "bought at some cost in the plausibility of basic assumptions" (p. 512). They noted (correctly) that our model assumes that cue and target information combine multiplicatively to drive a random-walk retrieval process

\footnotetext{
${ }^{1}$ Neither Model $2+1$ (Equations 1-3) nor the priming model (Equations 4-6) allow for residual switch costs at asymptotic SOAs because one $R T_{\text {Base }}$ parameter is used for all three transitions (cue repetitions, task repetitions, and task alternations). Arrington and Logan (2004a) and Logan and Bundesen (2004) presented a variation of Model 2, called Model 3, which allowed different values of $R T_{\text {Base }}$ for cue repetitions and task repetitions on the one hand and task alternations on the other. The complete version of Schneider and Logan's (2005) priming model specifies the compound-cue retrieval process that underlies target processing and allows $R T_{\text {Base }}$ to vary systematically between conditions. Thus, Model 3 and the full priming model can account for residual switch costs.
} 
and suggested that our assumption that the random walk does not begin until the target is presented is implausible. As we noted in Schneider and Logan (2005), this is a consequence of the multiplication of cues and targets in the calculation of drift rate, which is a common assumption in models of categorization subsumed in ITAM (e.g., Medin \& Shaffer, 1978; Nosofsky, 1984; Nosofsky \& Palmeri, 1997). The value of the target is approximately zero until it is presented, so the value of the product of cue and target information is approximately zero until the target is presented. The random-walk retrieval process does not begin until the drift rate is substantially greater than zero, so to simplify the mathematics of the model, we assumed that drift rate was zero until the target was presented.

Monsell and Mizon (2006) also suggested that our account of residual switch costs was implausible. Logan and Bundesen (2003) suggested that small differences between task repetitions and task alternations at the longest SOA of an experiment could reflect the upper tail of the distribution of cue encoding times. The plausibility of this claim can only be assessed by estimating the distribution of cue encoding times, which Monsell and Mizon did not do (but see Schneider \& Logan, 2005). Moreover, Logan and Bundesen (2003, p. 596) said explicitly that there could be true residual switch costs caused by other factors, which would produce a shift in $R T_{\text {Base }}$, and Arrington and Logan (2004a) and Logan and Bundesen (2004) presented models that allowed shifts in $R T_{\text {Base }}$ to capture true residual switch costs. Furthermore, Schneider and Logan (2005) explained cue-target congruency effects in terms of the random-walk retrieval process that is part of $R T_{\text {Base }}$ in most fits of our models.

Monsell and Mizon (2006) then suggested that we have trouble predicting the magnitude of true switch costs, citing our associative and semantic priming hypothesis for meaningful cues (Logan \& Schneider, 2006b; Schneider \& Logan, 2005) and our mediatorretrieval hypothesis for arbitrary cues (Logan \& Bundesen, 2004; Logan \& Schneider, 2006a). They seem to accept these accounts of our data (pp. 512-513), but they suggested that our ideas do not explain their data (though they seem to accept a mediator-retrieval account of the difference between meaningful word cues and "iconic" cues in their Experiment 3; see p. 503). We do not have ready explanations for the diversity of results in their experiments (beyond transition probability effects; see below), but neither do they.

Finally, Monsell and Mizon (2006) suggested that our "attempt to capture ... effects by adding assumptions about associative priming, mediator priming, and cue-cue transition priming ... dilutes the parsimony of [our] original account" (p. 514). We view these additional assumptions as natural developments of our model. In the Logan and Bundesen (2003) article and the articles that followed it, we framed our theory in terms of Logan and Gordon's (2001) executive control theory of visual attention (ECTVA), which is a special case of ITAM (Logan, 2002). ITAM is a very broad theory, incorporating nine formal models of attention, categorization, and memory as special cases. The modifications of our priming theory have been implemented in practice or in principle in the formal structure of ITAM and its ancestors. The parsimony of our approach stems from working within this one formalism and exploiting its computational machinery to account for various effects in explicitly cued task-switching performance.

\section{Monsell and Mizon's (2006) Challenge to Logan and Bundesen (2003)}

Monsell and Mizon (2006) responded to Logan and Bundesen's (2003) challenge to the reconfiguration view with empirical and theoretical challenges to Logan and Bundesen's position. Their empirical challenge addressed procedures involving two cues per task, arguing that true switch costs that decrease with SOA can be observed under conditions (described below) that are slightly different from Logan and Bundesen's and that the vanishingly small true switch costs found by Logan and Bundesen were contingent on the conditions they chose. Monsell and Mizon interpreted the reduction in true switch cost with SOA as evidence for endogenous reconfiguration and concluded that the explicit taskcuing procedure could measure endogenous control processes, contrary to Logan and Bundesen's claims. Their theoretical challenge was an account of explicitly cued performance in which subjects switch task sets whenever the cue changes. By this account (described in detail below), endogenous reconfiguration occurs for both task alternations and task repetitions, so the difference between them does not reflect a true switch cost (i.e., a pure measure of an endogenous control process).

\section{Response to the Empirical Challenges}

Reduction in true switch cost with SOA. Monsell and Mizon (2006) argued that a reduction in true switch cost with SOA is clear evidence for endogenous reconfiguration. We agree that endogenous reconfiguration can predict a reduction in true switch cost with SOA, but that prediction is not unique. Logan and Bundesen's (2003) Model $2+1$ incorporates endogenous reconfiguration, and that model clearly predicts a reduction in true switch cost with SOA. The prediction can be seen by comparing Equations 2 and 3, which represent RT for task repetitions and task alternations. The difference between the equations equals the mean time to switch task sets (i.e., $\mu_{s}$ ) when SOA $=0$, and approaches zero as SOA approaches infinity (i.e., true switch cost decreases with SOA). However, the priming model (Schneider \& Logan, 2005) also predicts a reduction in true switch costs as SOA increases. This can be seen by comparing Equations 5 and 6, which represent task repetitions and task alternations in that model. The difference between these equations equals the semantic or associative priming effect (i.e., $\mu_{u}-\mu_{a}$ ) when SOA $=0$, and approaches zero as SOA approaches infinity. Thus, a reduction in true switch cost with SOA is not uniquely predicted by reconfiguration models. The priming model, which assumes no reconfiguration, makes the same prediction.

Transition frequency. Monsell and Mizon (2006) reported six experiments that looked for a reduction in true switch cost with SOA in a procedure with two cues per task. The first three experiments were exploratory and led them to conclude that a reduction in true switch cost could be obtained in experiments in which the probability or frequency of a task switch was low. This conclusion was consistent with their results and consistent with a contrast between Logan and Bundesen's (2003) experiments, in which the probability of a task switch was .5 and true switch costs were small, and Mayr and Kliegl's (2003) experiments, in which the probability of a task switch was .33 and true switch costs were large. Monsell and Mizon's Experiments 4 and 6 manipulated the 
probability of different transitions and found larger true switch costs that decreased with SOA when task switches were less frequent, consistent with their conclusion.

Transition frequency is a problematic manipulation because it varies several things besides the probability of different transitions. Most importantly from our perspective, manipulating transition frequency also varies the probability that one cue will follow another. We calculated the conditional probabilities of presenting a specific cue on Trial $n$ given a specific cue on Trial $n-1$ for each condition in Monsell and Mizon's (2006) Experiments 4 and 6. The conditional probabilities, presented in Table 1, show that there was a predictive relationship between the cue on Trial $n-1$ and the cue on Trial $n$ for every condition except the last one in Experiment 6 (in Monsell and Mizon's notation, the 25/25/50 condition), which used the same transition probabilities we did. Subjects may have exploited this predictive information to facilitate cue encoding (Neely, 1977). Moreover, the probability of getting a cue for one task on Trial $n$ given a cue for the other task on Trial $n-1$ is confounded with the probability of a task switch. The lower the probability of a task switch, the lower the probability of getting a cue for one task given a cue for the other. Thus, the larger true switch costs observed in these experiments may reflect stimulus probability effects-subjects respond more slowly to infrequent stimulus sequences - instead of endogenous reconfiguration. The effects of stimulus probability on RT are well established and relatively well understood (Hyman, 1953; Laming, 1968). There is no need to invoke more complex processes (like endogenous reconfiguration) when simpler accounts are available. Transition frequency manipulations also affect longer sequences of cues than the immediate repetitions we have just discussed, and there is evidence that longer, implicitly learned task sequences can affect performance in task-switching experiments (Gotler, Meiran, \& Tzelgov, 2003; Heuer, Schmidtke, \& Kleinsorge, 2001; Koch, 2001). The important point from our perspective is that transition frequency can affect cue encoding as well as or instead of task switching. Indeed, an important goal of our research program has been to point out the importance of cue encoding in task-switching experiments.

Table 1

Conditional Probabilities of Presenting a Specific Cue on Trial $n$ Given a Specific Cue on Trial n- 1 in Monsell and Mizon's (2006) Experiments 4 and 6

\begin{tabular}{lcccc}
\hline $\begin{array}{c}\text { Experiment and } \\
\text { transition frequencies }\end{array}$ & $\mathrm{OlO}(\mathrm{CR})$ & $\mathrm{ElO}(\mathrm{TR})$ & $\mathrm{HIO}(\mathrm{TA})$ & $\mathrm{LIO}(\mathrm{TA})$ \\
\hline Experiment 4 & & & & \\
$0 / 25 / 75$ & 0 & .25 & .375 & .375 \\
$0 / 50 / 50$ & 0 & .50 & .25 & .25 \\
$0 / 75 / 25$ & 0 & .75 & .125 & .125 \\
Experiment 6 & & & & \\
$25 / 50 / 25$ & .25 & .50 & .125 & .125 \\
$25 / 25 / 50$ & .25 & .25 & .25 & .25 \\
\hline
\end{tabular}

Note. $\mathrm{O}, \mathrm{E}, \mathrm{H}$, and $\mathrm{L}$ represent the four different cues used in each experiment, with $\mathrm{O}$ and $\mathrm{E}$ assigned to one task and $\mathrm{H}$ and $\mathrm{L}$ assigned to the other. Thus, ElO indicates the probability of presenting cue $\mathrm{E}$ on Trial $n$ given cue $\mathrm{O}$ on Trial $n-1 . \mathrm{CR}=$ cue repetition; TR $=$ task repetition; $\mathrm{TA}=$ task alternation. 0/25/75 indicates Monsell and Mizon's notation for percentages of trials with cue repetitions, task repetitions, and task alternations, respectively (i.e., CR/TR/TA).
Our cue encoding approach to transition frequency is illustrated in an experiment by Schneider and Logan (2006). Subjects performed parity and magnitude judgments of single digits, cued by the words Odd-Even, Parity, High-Low, and Magnitude, with SOAs of $0,100,200,400$, and $800 \mathrm{~ms}$. Transition frequency was manipulated within subjects in separate sessions. There were three conditions: cue repetitions frequent, in which cue repetitions occurred on $70 \%$ of the trials and task repetitions and task alternations each occurred on $15 \%$ of the trials (70/15/15 in Monsell and Mizon's notation), task repetitions frequent, in which task repetitions occurred on $70 \%$ of the trials and cue repetitions and task alternations each occurred on $15 \%$ of the trials (15/70/15), and task alternations frequent, in which task alternations occurred on $70 \%$ of the trials and cue repetitions and task repetitions each occurred on $15 \%$ of the trials $(15 / 15 / 70)$. The mean RTs across subjects are plotted as points in Figure 1.

The data were analyzed by fitting the priming model (Equations 4-6) to the time-course functions, allowing different parameters for each condition. Consistent with our previous work, estimated cue encoding times were faster for cue repetitions than for task repetitions and faster for task repetitions than for task alternations in each frequency condition. Cue encoding times were also faster when transitions were frequent than when they were infrequent, and the ratio of frequent to infrequent cue encoding times was almost constant across transitions: It was $.837, .814$, and .823 for cue repetitions, task repetitions, and task alternations, respectively (see Table 2). Consequently, we fit the data with another model in which cue encoding time was free to vary between cue repetitions, task repetitions, and task alternations, but cue encoding time for frequent transitions was a constant proportion of cue encoding time for infrequent transitions. This model fit almost as well as the model with more free parameters, and the best-fitting proportion (ratio of frequent to infrequent) was .828. The predicted RTs from this model are plotted as lines in Figure 1. The values of the best-fitting parameters and measures of goodness of fit are presented in Table 2. The fit of the model and the constant relation between cue encoding times for frequent versus infrequent transitions led us to conclude that transition frequency affected cue encoding time, speeding cue encoding for frequent transitions. ${ }^{2}$

Our cue encoding analysis also provides an excellent account of Monsell and Mizon's (2006) data. We focus on their Experiment 6 because it includes cue repetitions, task repetitions, and task alternations, as well as four SOAs, so there are enough data points for a meaningful fit of our priming model to the data. We fit Equations $4-6$ to the 24 mean RTs from their Experiment 6

\footnotetext{
${ }^{2}$ The model fits within each transition probability condition assumed a common value of $R T_{\text {Base }}$ for all three transitions (cue repetitions, task repetitions, task alternations). Thus, the model fits assumed there were no residual switch costs. However, the model fits required a larger value of $R T_{\text {Base }}$ when task alternations were frequent $(15 / 15 / 70)$ than when cue repetitions were frequent $(70 / 15 / 15)$ and when task repetitions were frequent (15/70/15). Schneider and Logan (2006, Note 2) interpreted this difference in terms of interference in compound-cue memory retrieval from decaying cues. Cues for the irrelevant task would be more recent and contribute more to the interference when task alternations were frequent than when cue repetitions or task repetitions were frequent. Compound-cue retrieval begins after the target has been encoded, so these differences appear in $R T_{\text {Base }}$ instead of cue encoding.
} 

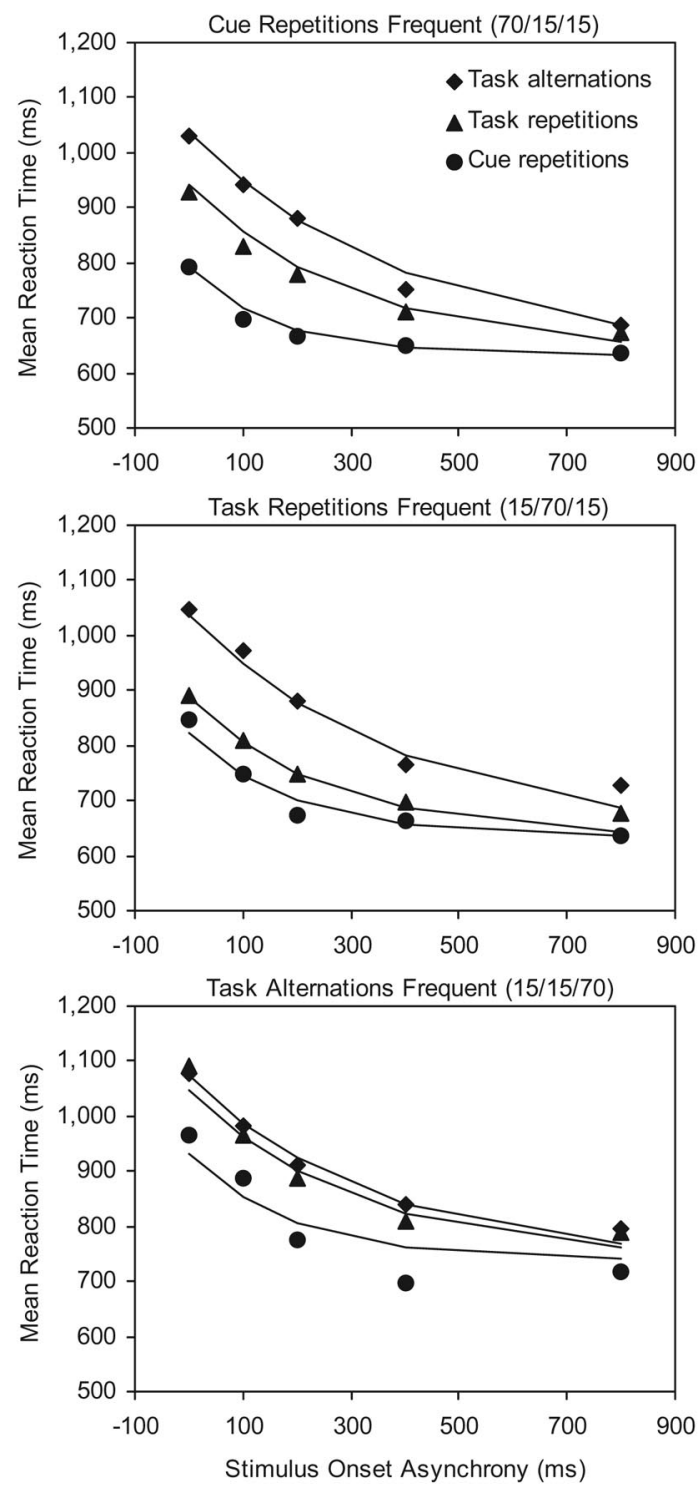

Figure 1. Mean reaction time for task alternations, task repetitions, and cue repetitions as a function of the stimulus onset asynchrony between the cue and the target when cue repetitions were frequent (top panel), task repetitions were frequent (middle panel), and task alternations were frequent (bottom panel). The points are observed data; the lines are predicted values from the priming model. Adapted with permission from "Priming cue encoding by manipulating transition frequency in explicitly cued task switching," by D. W. Schneider and G. D. Logan, 2006, Psychonomic Bulletin \& Review, 13, p. 148. Copyright 2006 Psychonomic Society, Inc.

(graciously provided by Stephen Monsell), using the Solver routine in Microsoft Excel to minimize the root mean squared deviation between observed and predicted values. In the first fit, we allowed separate cue encoding times for each transition in each condition. The values of the best-fitting parameters and measures of goodness of fit are presented in Table 2. Cue encoding time was faster for cue repetitions than for task repetitions and faster for task repetitions than for task alternations. Cue encoding time was also faster for frequent task repetitions than for infrequent task repeti- tions and faster for frequent task alternations than for infrequent task alternations, and the ratio of frequent to infrequent cue encoding times was similar for task repetitions and task alternations (.935 and .841, respectively). Consequently, we fit a restricted version of the priming model, in which cue encoding time varied freely between cue repetition, task repetition, and task alternation conditions, but cue encoding time for frequent transitions was constrained to be a constant proportion of cue encoding time for infrequent transitions. The values of the best-fitting parameters and measures of goodness of fit are also presented in Table 2. As in our data, this model fit well —not significantly worse than the model with more free parameters, $F(1,18)=3.12, p<.10$. The bestfitting proportion was .868 . The predicted RTs from this model are plotted as lines in Figure 2 (observed RTs are plotted as points). The fit of the model and the constant relation between cue encoding times for frequent and infrequent transitions suggest that a cue encoding account can explain Monsell and Mizon's data as well as it explains ours. There is no need to postulate endogenous reconfiguration or to propose different reconfiguration strategies for different conditions.

Our model fits to Monsell and Mizon's (2006) data revealed faster cue encoding times for task repetitions than for task alter-

Table 2

Values of Best-Fitting Parameters and Measures of Goodness of Fit for 6-Parameter and 5-Parameter Priming Models Fit to Mean Reaction Times From Monsell and Mizon's (2006)

Experiment 6 and for the 6-Parameter Priming Model Fit to Schneider and Logan's (2006) Experiment

\begin{tabular}{lccc}
\hline $\begin{array}{c}\text { Parameter or } \\
\text { measure of } \\
\text { goodness of fit }\end{array}$ & $\begin{array}{c}\text { 6-Parameter } \\
\text { M\&M }\end{array}$ & $\begin{array}{c}\text { 5-Parameter } \\
\text { M\&M }\end{array}$ & $\begin{array}{c}\text { 6-Parameter } \\
\text { S\&L }\end{array}$ \\
\hline$\mu_{r \text {-Freq }}$ & & & $\mathbf{1 5 9}$ \\
$\mu_{r \text {-Infreq }}$ & 229 & 228 & 191 \\
$\mu_{a-\text { Freq }}$ & 305 & $\mathbf{2 9 2}$ & $\mathbf{2 5 5}$ \\
$\mu_{a-\text { Infreq }}$ & 326 & 336 & 308 \\
$\mu_{u \text {-Freq }}$ & 387 & $\mathbf{3 9 4}$ & $\mathbf{3 3 4}$ \\
$\mu_{u \text {-Infreq }}$ & 460 & 454 & 403 \\
$f$ & & .868 & .828 \\
$R T_{\text {Base }}$ & 628 & 628 & 633 \\
$R T_{\text {Base-CRF,TRF }}$ & & & 740 \\
$R T_{\text {Base-TAF }}$ & & & .986 \\
$r$ & & & 21 \\
\hline MSD & 990 & 13 & \\
\hline
\end{tabular}

Note. $\quad \mathrm{M} \& \mathrm{M}=$ Monsell and Mizon (2006); $\mathrm{S} \& \mathrm{~L}=$ Schneider and Logan (2006); $\mu_{r}=$ mean cue encoding time for cue repetitions; $\mu_{a}=$ mean cue encoding time for task repetitions; $\mu_{u}=$ mean cue encoding time for task alternations; Freq $=$ conditions in which the associated transition is frequent; Infreq = conditions in which the associated transition is infrequent; $f=$ proportion of cue encoding time for frequent transitions relative to infrequent transitions; $R T_{B a s e}=$ base reaction time for fits to Monsell and Mizon's data; $R T_{\text {Base-CRF,TRF }}=$ base reaction time for all transitions when cue repetitions and task repetitions were frequent in fits to Schneider and Logan's data; $R T_{\text {Base-TAF }}=$ base reaction time for all transitions when task alternations were frequent in fits to Schneider and Logan's data; $r=$ correlation between observed and predicted values; $R M S D=$ root mean squared deviation between observed and predicted values, which was minimized in optimizing the fit. Parameter values in bold were calculated rather than estimated in the 5-parameter M\&M model fit and the 6-parameter S\&L model fit (i.e., $\mu_{r-F r e q}=f \cdot \mu_{r-\text { Infreq, }} \mu_{a-\text {-Freq }}=f \cdot \mu_{a-\text { Infreq }}$, and $\mu_{u-\text { Freq }}=f \cdot \mu_{u-\text { Infreq }}$ ). 

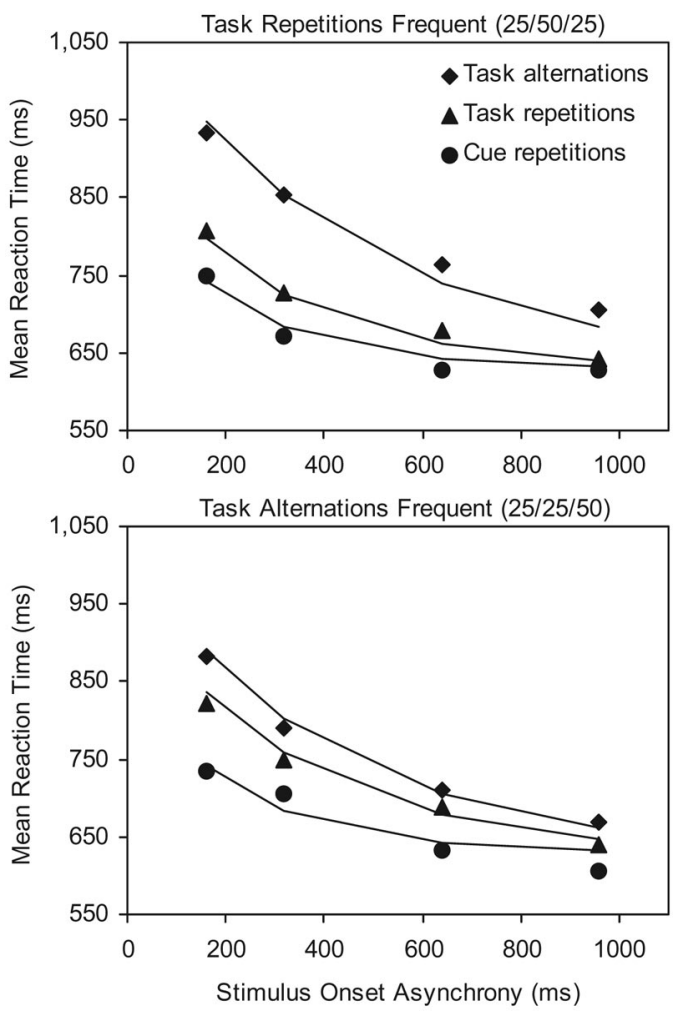

Figure 2. Mean reaction time for task alternations, task repetitions, and cue repetitions as a function of the stimulus onset asynchrony between the cue and the target when task repetitions were frequent (top panel) and task alternations were frequent (bottom panel). The points are observed data from Experiment 6 of Monsell and Mizon (2006); the lines are predicted values from the priming model.

nations regardless of transition frequency. We interpret these differences as reflecting semantic or associative priming of task repetitions. Monsell and Mizon claim their Experiment 6 was "modeled closely on Logan and Bundesen (2003, Experiment 3)" (p. 507), but in fact it was a closer replication of Schneider and Logan (2005, Experiment 1), which also used the cues Odd, Even, High, and Low to cue parity and magnitude judgments of single digits. (Logan and Bundesen's Experiment 3 used Odd-Even, Parity, High-Low, and Magnitude as cues.) This is an unfortunate choice for Monsell and Mizon's purposes because the cues assigned to the same task are strongly associated with each other. As Schneider and Logan reported, the probabilities of generating Odd given Even and generating Even given Odd are .621 and .558, respectively, and the probabilities of generating High given Low and generating Low given High are .777 and .655, respectively, in the Nelson, McEvoy, and Schreiber (1999) free-association norms. Thus, it is very likely that cue encoding was facilitated by semantic or associative priming on task-repetition trials, which would inflate true switch costs by reducing task-repetition RT without affecting task-alternation RT (see below; see also Logan \& Schneider, 2006b). Moreover, as noted previously, the priming model predicts that this priming effect will decrease as SOA increases (which can be seen by subtracting Equation 5 from Equation 6), mimicking the reduction in true switch costs predicted by endogenous reconfiguration.

Meaningful versus arbitrary cues and semantic or associative priming. Transition frequency is not the only factor that affects the magnitude of true switch costs. Several experiments have shown that arbitrary cues, which are unrelated to the tasks they indicate (e.g., $B$ or $W$ for magnitude judgments; $G$ or $S$ for parity judgments), produce larger switch costs than meaningful cues whose conventional meanings describe the response categories or the tasks to be performed (e.g., High-Low or Magnitude for magnitude judgments; Odd-Even or Parity for parity judgments; Arbuthnott \& Woodward, 2002; Mayr \& Kliegl, 2000; Miyake, Emerson, Padilla, \& Ahn, 2004). Indeed, Mayr and Kliegl's (2003) experiments, which produced large true switch costs, involved arbitrary cues, whereas Logan and Bundesen's (2003) experiments, which produced small true switch costs, involved meaningful cues.

Figure 3 shows 24 cue encoding benefits and true switch costs, averaged across SOA, from 24 conditions of our published experiments (Arrington \& Logan, 2004a, 2005; Logan \& Bundesen, 2004; Logan \& Schneider, 2006a, 2006b; Schneider \& Logan, 2005, 2006). The benefits and costs are plotted as cumulative distribution functions, which were created by rank ordering the differences and plotting each difference against its cumulative probability. There was substantial variability in each effect. Cue encoding benefits were large, ranging from 52 to $367 \mathrm{~ms}$, with a mean of $154 \mathrm{~ms}$. True switch costs were not always "vanishingly small," but they were almost always smaller than cue encoding benefits, ranging from 8 to $185 \mathrm{~ms}$, with a mean of $75 \mathrm{~ms}$. Cue encoding benefits were larger than true switch costs in 21 of the 24 conditions, contrary to Monsell and Mizon's (2006) suggestion that "perhaps the more typical finding is that [true switch costs]

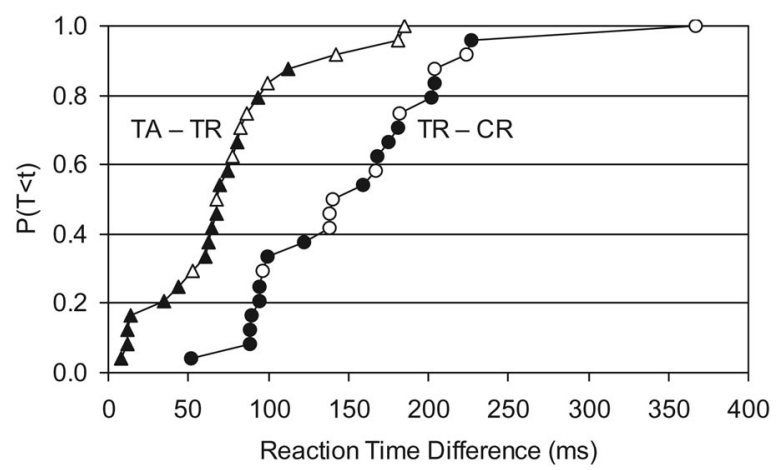

Figure 3. Cumulative distribution functions for differences in reaction time between task alternations and task repetitions (TA - TR) and between task repetitions and cue repetitions (TR - CR) in 24 conditions (Arrington \& Logan, 2004a, 2005, Experiment 3; Logan \& Bundesen, 2003, Experiments 3 \& 4; Logan \& Bundesen, 2004, Experiment 1, word-first block 1, letter-first block 1; Experiment 2, word-first block 1, letter-first block 2; Logan \& Schneider, 2006a, Experiments 1 \& 2; Logan \& Schneider, 2006b; Schneider \& Logan, 2005, 2006). Filled symbols indicate conditions with meaningful cues and unfilled symbols indicate conditions with arbitrary cues. 
and [cue encoding benefits] are of roughly equal orders of magnitude when both are measured" (p. 514). ${ }^{3}$

Nine of the conditions plotted in Figure 3 used arbitrary cues (represented by open symbols) and 15 used meaningful cues (represented by filled symbols). True switch costs were much larger for arbitrary cues $(M=109 \mathrm{~ms})$ than for meaningful cues $(M=54 \mathrm{~ms})$. Cue encoding benefits were also larger for arbitrary cues $(M=185 \mathrm{~ms})$ than for meaningful cues $(M=100 \mathrm{~ms})$. Two of the experiments compared meaningful and arbitrary cues within subjects (Logan \& Bundesen, 2004), replicating these results. True switch costs were larger for arbitrary cues $(M=134 \mathrm{~ms})$ than for meaningful cues $(M=10 \mathrm{~ms})$; cue encoding benefits were also larger for arbitrary cues $(M=232 \mathrm{~ms})$ than for meaningful cues $(M=182 \mathrm{~ms})$.

These differences between arbitrary and meaningful cues are independent of transition frequency. In all but three conditions (those from Schneider \& Logan, 2006), the transition frequencies were $25 \%$ cue repetitions, $25 \%$ task repetitions, and $50 \%$ task alternations (i.e., 25/25/50 in Monsell \& Mizon's [2006] notation). These data demonstrate that it is possible to get large true switch costs with these transition frequencies, contrary to Monsell and Mizon's assertion.

Another factor besides transition frequency and cue type (arbitrary vs. meaningful) that accounts for variability in cue encoding benefits and true switch costs is semantic or associative priming. Meaningful cues that indicate the same task are necessarily related because their conventional meanings refer to the same thing. Meaningful cues that indicate different tasks are necessarily unrelated because their conventional meanings refer to different things. Averaged over all conditions in Figure 3, true switch costs were larger when cues assigned to the same task were associated $(M=$ $96 \mathrm{~ms}$ ) than when they were not associated ( $M=70 \mathrm{~ms})$. Cue encoding benefits were smaller for associated cues $(M=110 \mathrm{~ms})$ than for unassociated cues $(M=163 \mathrm{~ms})$. Logan and Schneider (2006b) assessed priming directly and showed that these differences reflect changes in task-repetition RT rather than changes in task-alternation or cue-repetition RT. They used the words Day, Night, King, Queen, Salt, Pepper, Noun and Verb as cues indicating parity and magnitude judgments of digits. In the associatedwithin condition, associated words were assigned to the same task (e.g., Day and Night cued magnitude judgments; King and Queen cued parity judgments). In the associated-between condition, associated words were assigned to different tasks (e.g., Day and King cued magnitude; Night and Queen cued parity). In the unassociated condition, none of the words assigned to either task were associated (e.g., Day and King cued magnitude; Salt and Noun cued parity). Cue repetition RT was very similar across conditions $(M \mathrm{~s}=895,890$, and $913 \mathrm{~ms}$ for associated-within, associatedbetween, and unassociated, respectively) as was task alternation RT $(M \mathrm{~s}=1,175,1,174$, and $1,217 \mathrm{~ms}$ for associated-within, associated-between, and unassociated, respectively). However, task repetition RT was much faster in the associated-within condition $(M=1,033 \mathrm{~ms})$ than in the associated-between and unassociated conditions ( $M \mathrm{~s}=1,114$ and $1,117 \mathrm{~ms}$, respectively). These data suggest associative or semantic priming facilitates RT for task repetitions (because the preceding cue is related to the current one) but not for cue repetitions (because the preceding cue is identical to the current one and identity priming is stronger than associative or semantic priming) or task alternations (because the preceding cue is unrelated to the current one). Thus, the opposing changes in true switch costs and cue encoding benefits are due to a changing baseline rather than a difference in reconfiguration processes.

\section{Response to Monsell and Mizon's Theoretical Challenge}

Monsell and Mizon (2006) claimed that "Task-set preparation is, ex hypothese, a voluntary process and may be discouraged under some circumstances" (p. 500). They suggested that a high probability of a task switch discourages this voluntary process and undermines the chances of observing true switch costs in the explicit task-cuing procedure:

\begin{abstract}
Our interpretation of these effects of switch probability is that, given a relatively high expectation that the task will change, participants tend to engage in some sort of preparation for the other task either before the cue onset or, if a cue change strongly predicts a task change, as soon as a cue change is detected, or both. Such preparation might take several forms. Participants might tend to move their control state to one "neutral" between the two task sets-in which case interpreting the cue would require further reconfiguration on [task repetition] trials (back to the previous state) as well as on [task alternation] trials (on to the competing state). Or the participant might probability-match and reconfigure for the other task on a proportion of trials determined by their estimate of the probability of a task change. When their guess was wrong ([task repetition] trials), they would have to reconfigure again; thus, following the cue, full [task-set reconfiguration] would be needed on a substantial proportion of [task repetition] trials, and no [task-set reconfiguration] would be needed on a substantial proportion of [task alternation] trials. Either way, the logic of the contrast between the effects of preparation on [task alternation] and [task repetition] trials is undermined if participants do not engage in substantially more task-set preparation on trials in which the cue signals a task change than on trials in which it does not. (p. 511)
\end{abstract}

Monsell and Mizon (2006) made three claims here that require strong assumptions. One requires further theoretical development to be evaluated properly and the other two appear to be contradicted by the data. First, the idea that subjects might change their control state "to one neutral between the two task sets" assumes that subjects can in fact adopt a neutral control state. We believe that this claim can only be justified in the context of a formal model that explicitly defines the possible control states and the mechanisms that govern transitions between them (e.g., Logan \& Gordon, 2001). Our priming model assumes discrete states. Subjects are either in one state or another; there is no neutral state in between them. Gilbert and Shallice's (2002) parallel distributed processing model assumes control states that are attractor points in a continuous state space. Neutral states are possible in their model, but they are unstable. The attractor states compete in a winnertake-all network, and the slightest bit of noise can drive the current state inexorably toward one of the attractor states. Moreover, it is clear how to drive their model into one of its control states (by

\footnotetext{
${ }^{3}$ Monsell and Mizon (2006) used different terminology than we have used throughout our articles. The text within brackets in this quote and subsequent ones substitutes our terminology for theirs. In this case, they refer to true switch costs as task-change effects and cue encoding benefits as cue-change effects.
} 
activating a task demand unit), but it is not clear how to drive it into a neutral state.

Second, the idea that high probabilities of task change invite subjects to reconfigure before cue onset predicts that differences between cue repetitions, task repetitions, and task alternations will diminish as switch probability increases and vanish if it is high enough. Ultimately there will be no difference between transitions. Moreover, switch probability should have a strong effect on cue repetitions (because subjects do not switch when switch probability is low and switch when switch probability is high) but it should have no effect on task alternations (because subjects always switch). The data in Figures 1 and 2 contradict these predictions. In Schneider and Logan's (2006) data, cue encoding times were slower for infrequent transitions than for frequent transitions regardless of the type of transition. In particular, mean cue encoding time for cue repetitions was no slower when task alternations were frequent (so switches were frequent) than when task repetitions were frequent (so switches were infrequent). In Monsell and Mizon's (2006) data, switch probability had strong effects on cue encoding times for task alternations but no effect on cue encoding times for cue repetitions. Thus, our data and Monsell and Mizon's own data provide no support for their idea that subjects tend to reconfigure on all trials before cue onset when switch probability is high.

Third, the idea that high switch probabilities lead subjects to reconfigure whenever the cue changes predicts that they must reconfigure twice for task repetitions (to the competing task and then back to the original task) but only once for task alternations (to the competing task). If subjects did this on every trial, or on more than half of the trials, then RT for task repetitions should be longer than RT for task alternations, reversing the switch cost. We did not observe this reversal in any of the 24 conditions in our published experiments (the task alternation [TA] - task repetition [TR] differences in Figure 3 are all positive), and Monsell and Mizon (2006) did not observe it in any of their six experiments, suggesting that the probability of reconfiguration whenever the cue changed must have been substantially smaller than 0.5 .

Monsell and Mizon (2006) made further claims about subjects' strategies in the explicit task-cuing procedure that lead to testable predictions. According to Monsell and Mizon, "The claim that the [reduction in true switch costs with SOA] in the [explicit task-] cuing paradigm measures endogenous task-set preparation assumes that (a) participants reconfigure task set when the cue indicates a change in task and (b) participants do not reconfigure task set (because they do not need to) when the cue indicates a task repeat" (p. 500). This is essentially the sequential task comparison strategy noted earlier. To account for performance in Logan and Bundesen's (2003) experiments, Monsell and Mizon proposed a sequential cue comparison strategy, which assumes that

following cue onset, information about whether the cue has changed is surely available early (via a crude detection of repetition/ difference), before identification of the cue and retrieval of the task. If a cue change is associated with a high probability of a task change, it may be a tempting strategy to begin to reconfigure as soon as a changed cue is detected, reversing the process if the cue, when interpreted, turns out to signal the same task as before.... If the conditions are such that participants frequently reconfigure task set even on [task repetition] trials, then evidently the difference in performance or in the effects of preparation between [task alternation] and [task repetition] trials will be a poor index of [task-set reconfiguration]. (p. 500)

They suggested that the conditions of Logan and Bundesen's (2003) experiments, which prevail in our subsequent studies (except for two conditions in Schneider \& Logan, 2006), are likely to induce reconfiguration for task repetitions because the probability of a task switch is relatively high $(p=.5)$ and the probability of a task switch given a cue switch is also high $(p=.66)$. Thus, they argued that our results reflect reconfiguration for both task repetitions and task alternations and not the priming of cue encoding we have proposed.

Our response to this challenge is to test the assumption on which Monsell and Mizon's (2006) sequential cue comparison strategy rests: "Information about whether the cue has changed is surely available early ... before identification of the cue" (p. 500). We tested this assumption by conducting an experiment that was intended to measure the time at which information about whether the cue has changed is available and to measure the time at which information about the identity of the cue is available. Monsell and Mizon assumed explicitly that information about cue change is available before information about cue identity, so evidence to the contrary would falsify their assumption and their sequential cue comparison strategy, which is a critical part of their theoretical challenge to our priming model.

\section{Testing Sequential Comparison Strategies}

We conducted an experiment to measure the time required to compare cues, compare tasks, and identify tasks. Each trial presented a cue indicating which task to perform, followed by a target on which the task was to be performed, like conventional experiments with the explicit task-cuing procedure. However, we required subjects to respond to the cue before the target was presented, and then respond to the target in accordance with the cue. The responses to the target yielded RTs and accuracies that could be analyzed in the same way as conventional explicit task-cuing experiments, sorting trials into cue repetitions, task repetitions, and task alternations, and looking for differences between them. The responses to the cue yielded RTs and accuracies that could reveal the time at which information about cue change and cue identity were available, to test the critical assumption underlying Monsell and Mizon's (2006) interpretation of our previous experiments.

Subjects were required to respond to the cue in three different ways in different experimental blocks. In the same cue condition, they reported whether the current cue was the same as or different from the cue on the preceding trial. RT in this condition reflects the time at which information about cue change is available. In the same task condition, subjects reported whether the cue on the current trial indicated the same task as the cue on the previous trial. $\mathrm{RT}$ in this condition reflects the time at which information about task change is available. In the name task condition, subjects reported which task was indicated by the current cue. RT in this condition reflects the time at which task identity is available Monsell and Mizon's (2006) sequential cue comparison strategy assumes that information about cue change is available well before information about cue identity, so cue RT should be much faster in the same cue condition than in the name task condition.

The contrast between the name task and same task conditions bears on the plausibility of our compound retrieval cue strategy. 
The name task condition requires subjects to identify the task indicated by the current cue, which is the essential computation underlying our priming model (see Arrington, Logan, \& Schneider, in press). The same task condition requires subjects to remember the task from the previous trial, identify the task indicated by the current cue, and compare the previous task with the current one, which is the essential computation underlying the sequential task comparison strategy. The extra computations in the same task condition should increase cue RT relative to the name task condition. This difference in cue RT quantifies the benefit subjects could gain by adopting our compound retrieval cue strategy instead of the sequential task comparison strategy. The greater the benefit, the more likely subjects are to use our strategy; the greater the benefit, the greater the plausibility of our priming account of explicitly cued performance.

The target RTs should provide further insight into the viability of the competing accounts of explicitly cued performance. Target RT should be fast if the response to the cue is part of normal processing in the explicit task-cuing procedure. If the response to the cue requires subjects to use processes they normally would not use, then target RT may be prolonged substantially. Thus, the cue task that yields the fastest task RTs is most likely to be the one subjects normally perform in explicitly cued performance (Arrington et al., in press). If subjects normally use the sequential cue comparison strategy, target RTs should be faster in the same cue condition than in the name task condition. If subjects normally use the compound retrieval cue strategy, target RTs should be faster in the name task condition than in the same cue condition.

\section{Method}

Subjects. Thirty people from the Vanderbilt University community served for course credit or payment.

Apparatus and stimuli. The stimuli were displayed on Sony Trinitron monitors controlled by Dell Dimension computers. Responses were collected from the $z, x$. (period), and / keys of the computer keyboard. There were four displays on each trial. The first was a fixation display, which consisted of two plus signs (+). One appeared above the position the cue would occupy and one appeared below the position the target would occupy. The second was a cue display, which contained the word Magnitude, Parity, High-Low, or Odd-Even presented in the center of the screen. The third was a cue-plus-target display, which contained the cue and the target. The target was a single digit from 1 to 9 excluding 5. It appeared directly below the cue. The cue was presented in the same position it occupied in the cue display, so it appeared as if the cue was displayed continuously and was joined by the target after the subject responded to the cue. The fourth display was a blank screen that was exposed until the beginning of the fixation display for the next trial.

Each letter and digit was $7 \mathrm{~mm}$ high $\times 4 \mathrm{~mm}$ wide. The cues were $7 \mathrm{~mm}$ high $\times 28$ (Parity), 37 (Odd-Even and High-Low), or 43 (Magnitude) $\mathrm{mm}$ wide. Viewing distance was not controlled but was approximately $60 \mathrm{~cm}$. At this distance, $1 \mathrm{~cm}$ is approximately $1^{\mathrm{o}}$ of visual angle.

Procedure. Each trial began with the fixation display exposed for $500 \mathrm{~ms}$. Then the cue display was exposed until $100 \mathrm{~ms}$ after subjects responded to the cue (i.e., the interval between the response to the cue and the onset of the cue-plus-target display was
$100 \mathrm{~ms}$ ). Then the cue-plus-target display was exposed until subjects responded to the target. Then the blank display was exposed for $1,000 \mathrm{~ms}$, whereupon the next trial began. All subjects performed magnitude or parity judgments on the digit targets, according to the cue presented immediately before each target. All subjects performed same cue, same task, and name task judgments on the cue in separate blocks. The order of cue-task conditions was counterbalanced across subjects, with five subjects receiving each of the six possible orders of conditions. As in previous experiments, we used two cues for each task: name cues (Magnitude, Parity), which named the task to be performed, and mapping cues (High-Low, Odd-Even), which named the response categories and category-to-response mapping.

In the same cue condition, subjects were instructed to report whether the current cue was the same as or different from the cue on the previous trial by pressing the $z$ or $x$ key with their left hand. Thus, if the cue on the current trial was High-Low and the cue on the previous trial was High-Low, they would report "same." If the cue on the current trial was High-Low and the cue on the previous trial was Magnitude, Parity, or Odd-Even, they would report "different." Subjects were told to respond "same" on the first trial of each block.

In the same task condition, subjects were instructed to report whether the task indicated by the current cue was the same as or different from the task indicated by the previous cue by pressing the $z$ or $x$ key with their left hand. Thus, if the cue on the current trial was High-Low and the cue on the previous trial was HighLow or Magnitude, they would report "same." If the cue on the current trial was High-Low and the cue on the previous trial was Parity or Odd-Even, they would report "different." Subjects were told to respond "same" on the first trial of each block.

In the name task condition, subjects were instructed to report the task that was indicated by the current cue by pressing the $z$ or $x$ key with their left hand. Thus, if the current cue was High-Low or Magnitude, they would report "high-low task" or "magnitude task." If the current cue was Odd-Even or Parity, they would report "odd-even task" or "parity task."

The experiment consisted of 768 trials, divided into three blocks of 256 trials. Each block consisted of eight replications of the basic 32-trial design, constructed from the factorial combination of four cues and eight targets. Each set of 32 trials was randomized separately for each subject. Subjects were given breaks every 128 trials. Instructions were given verbally at the beginning of the experiment and appeared on the screen at the beginning of each block. Subjects were told to respond to the cue by pressing the $z$ or $x$ key with the middle and index fingers of their left hands. All subjects pressed the $z$ key for "same" and the $x$ key for "different" in the same cue and same task conditions, and all subjects pressed the $z$ key for "oddeven" or "parity" and the $x$ key for "high-low" or "magnitude" in the name task condition. Subjects were told to respond to the target by pressing the . (period) or / key with the index and middle fingers of their right hands. All subjects pressed . (period) for "high" and "odd" and / for "low" and "even." Post-it notes with the mapping rules were attached to the bottom of the computer screen to refresh subjects' memories, when necessary. 


\section{Results and Discussion}

Cue and target responses were sorted into cue repetitions, task repetitions, and task alternations post hoc. Mean cue RT and mean target RT were calculated for correct responses and trials with RTs less than 5,000 ms for each combination of cue task (same cue, same task, name task), transition (cue repetition, task repetition, task alternation), and cue type (name cue [Magnitude, Parity], mapping cue [High-Low, Odd-Even]) for each subject. Percentage of correct responses was calculated for each condition for each subject.

Cue RT. Mean RTs and the accuracy of cue responses are presented in Table 3 as a function of cue task, transition, and cue type. A 3 (cue task) $\times 3$ (transition) $\times 2$ (cue type) analysis of variance (ANOVA) conducted on the mean RTs yielded significant main effects of cue task, $F(2,58)=13.20, p<.01, M S E=$ 173,963.34; transition, $F(2,58)=120.01, p<.01, M S E=$ $12,527.54$; and cue type, $F(1,29)=27.04, p<.01, M S E=$

Table 3

Mean Reaction Time (ms) and Percentage of Correct Responses for Cue Responses and Target Responses as a Function of Task (Name Task, Same Cue, Same Task), Cue Type (Name Cue vs. Mapping Cue), and Transition (Cue Repetition, Task Repetition, Task Alternation)

\begin{tabular}{|c|c|c|c|c|c|}
\hline $\begin{array}{c}\text { Task and cue } \\
\text { type }\end{array}$ & & $\mathrm{CR}$ & TR & TA & $M$ \\
\hline & & \multicolumn{4}{|c|}{ Cue response data } \\
\hline \multicolumn{6}{|l|}{ Name task } \\
\hline \multirow[t]{2}{*}{ Name cue } & RT & $712(32)$ & $871(41)$ & $884(29)$ & 822 \\
\hline & PC & $99(0.3)$ & $99(0.4)$ & $99(0.3)$ & 99 \\
\hline \multirow{2}{*}{ Mapping cue } & RT & 778 (33) & $954(35)$ & $966(33)$ & 873 \\
\hline & $\mathrm{PC}$ & $99(0.3)$ & $97(0.7)$ & $98(0.4)$ & 98 \\
\hline \multicolumn{6}{|l|}{ Same cue } \\
\hline \multirow[t]{2}{*}{ Name cue } & RT & $861(36)$ & $953(43)$ & $955(35)$ & 923 \\
\hline & $\mathrm{PC}$ & $95(0.8)$ & $98(0.5)$ & $98(0.3)$ & 98 \\
\hline \multirow[t]{2}{*}{ Mapping cue } & RT & $918(34)$ & $976(44)$ & $965(38)$ & 953 \\
\hline & $\mathrm{PC}$ & $95(1.0)$ & $99(0.5)$ & $99(0.3)$ & 98 \\
\hline \multicolumn{6}{|l|}{ Same task } \\
\hline \multirow[t]{2}{*}{ Name cue } & RT & $935(38)$ & $1069(43)$ & $1184(52)$ & 1063 \\
\hline & $\mathrm{PC}$ & $96(0.7)$ & $95(0.7)$ & $96(0.6)$ & 96 \\
\hline \multirow[t]{2}{*}{ Mapping cue } & RT & $943(36)$ & $1128(40)$ & $1242(51)$ & 1064 \\
\hline & $\mathrm{PC}$ & $96(0.5)$ & $96(0.7)$ & $96(0.6)$ & 96 \\
\hline & & & \multicolumn{3}{|c|}{ Target response data } \\
\hline \multicolumn{6}{|l|}{ Name task } \\
\hline \multirow{2}{*}{ Name cue } & RT & $1576(56)$ & $1707(58)$ & $1866(64)$ & 1716 \\
\hline & $\mathrm{PC}$ & $96(0.9)$ & $95(0.9)$ & $93(0.9)$ & 95 \\
\hline \multirow[t]{2}{*}{ Mapping cue } & RT & $1600(49)$ & $1775(50)$ & $1898(61)$ & 1758 \\
\hline & $\mathrm{PC}$ & $96(0.9)$ & $95(0.6)$ & $94(0.8)$ & 95 \\
\hline \multicolumn{6}{|l|}{ Same cue } \\
\hline \multirow{2}{*}{ Name cue } & RT & $1793(56)$ & $2012(81)$ & 2018 (73) & 1941 \\
\hline & $\mathrm{PC}$ & $93(1.2)$ & $96(1.1)$ & $93(0.9)$ & 94 \\
\hline \multirow[t]{2}{*}{ Mapping cue } & RT & $1837(61)$ & $1954(69)$ & $1967(68)$ & 1919 \\
\hline & $\mathrm{PC}$ & $95(0.9)$ & $95(1.1)$ & $94(0.7)$ & 95 \\
\hline \multicolumn{6}{|l|}{ Same task } \\
\hline \multirow[t]{2}{*}{ Name cue } & RT & $1880(64)$ & $2003(65)$ & $2253(74)$ & 2045 \\
\hline & $\mathrm{PC}$ & $96(0.6)$ & $96(0.8)$ & $92(1.0)$ & 95 \\
\hline \multirow[t]{2}{*}{ Mapping cue } & RT & $1849(63)$ & $2048(63)$ & $2252(75)$ & 2050 \\
\hline & PC & $96(0.9)$ & $95(1.0)$ & $93(0.6)$ & 95 \\
\hline
\end{tabular}

Note. Standard errors are in parentheses. $\mathrm{CR}=$ cue repetition; $\mathrm{TR}=$ task repetition; $\mathrm{TA}=$ task alternation; $\mathrm{RT}=$ reaction time; $\mathrm{PC}=$ percentage of correct responses.
12,282.78. The interaction between cue task and transition was significant, $F(4,116)=15.80, p<.01, M S E=10,925.28$, and the interaction between cue task and cue type approached significance, $F(2,58)=2.66, p=.08, M S E=10,165.77$. A 3 (cue task) $\times 3$ (transition) $\times 2$ (cue type) ANOVA on the percentages of correct responses yielded a significant main effect of cue task, $F(2,58)=$ $32.53, p<.01, M S E=11.59$, and a significant interaction between cue task and transition, $F(4,116)=10.58, p<.01, M S E=$ 9.42 .

The most important comparison theoretically is between mean RT in the same cue and name task conditions. Monsell and Mizon's (2006) sequential cue comparison strategy assumes that same cue RT will be substantially faster than name task RT. However, the data showed the opposite trend, contrary to the prediction. Averaged over transition and cue type, mean RT was slower in the same cue condition $(M=938 \mathrm{~ms})$ than in the name task condition $(M=860 \mathrm{~ms})$. The difference approached significance, $F(1,58)=3.12, p=.08, M S E=173,963.34$.

The contrast between name task and same cue conditions was qualified by two interactions. One was between cue task and transition, which is plotted in Figure 4. The figure shows that cue RTs were faster in the name task condition than in the same cue condition for all three transitions, but the difference was larger for cue repetitions $(147 \mathrm{~ms})$ than for task repetitions $(51 \mathrm{~ms})$ and task alternations (35 ms). Fisher's Least Significant Difference (LSD) test showed that the difference was significant $(p<.05)$ for cue repetitions but not for task repetitions or task alternations. One possible explanation for the interaction is a difference in response probability between conditions. In the name task condition, the two responses were equally probable because each task was cued on half of the trials. In the same cue condition, the "same" response occurred on $25 \%$ of the trials and the "different" response occurred on $75 \%$ of the trials. This imbalance in probability would slow cue RT for cue repetitions and speed RT for task repetitions and task alternations. The slowing would enhance the difference between same cue and name task conditions for cue repetitions, and the speeding would diminish the difference between same cue and name task conditions for task repetitions and task alternations. Regardless of the details of the interpretation, the critical point to be taken from this interaction is that the prediction drawn from Monsell and Mizon's (2006) sequential cue comparison hypothesis - that name task RTs should be significantly slower than same cue RTs-was not confirmed for any of the transitions.

The second interaction, between cue task and cue type, allows us to address the possibility that name task RTs are faster than same cue RTs because the responses are more compatible with the stimuli in the name task condition. ${ }^{4}$ The name task responses may be more similar to the stimuli (e.g., respond "magnitude" to the cue Magnitude) than the responses in the same cue condition (e.g., respond "same" when Magnitude occurred on two successive trials), and this increased similarity may speed cue RT. This possibility is mitigated somewhat by two aspects of the procedure in the name task condition: The cue responses were manual, not vocal, and two cues were mapped onto each cue response. Arrington et al. (in press) compared several different versions of the

\footnotetext{
${ }^{4}$ We are grateful to Nachshon Meiran for pointing out this interpretation.
} 
name task condition and found that subjects were especially fast when they gave a separate vocal response to each cue, essentially reading the cue aloud $(M=606 \mathrm{~ms})$. The same 1:1 mapping of cues onto keypress responses produced much longer cue RTs ( $M=765 \mathrm{~ms})$, suggesting that vocal responses were more compatible with the cues than keypress responses. Arrington et al. also found that cue RT was longer when subjects responded vocally by naming the task instead of the cue $(M=725 \mathrm{~ms})$, suggesting that 2:1 mappings of cues to responses are less compatible than $1: 1$ mappings. Cue RT was also long for keypress responses that indicated which task was required $(M=741 \mathrm{~ms})$, suggesting that 2:1 mappings of cues onto keypress responses are not as compatible as 1:1 mappings of cues onto vocal responses. Their data suggest that our name task condition, which involved a 2:1 mapping of cues onto keypress responses, was not likely to benefit from a high degree of stimulus-response compatibility.

Our data provide a direct test of the compatibility account. We found that 24 of the 30 subjects responded faster with name cues (Magnitude and Parity) than with mapping cues (High-Low and Odd-Even), and cue RTs were $77 \mathrm{~ms}$ faster with name cues than with mapping cues. ${ }^{5,6}$ These effects suggest that subjects may have used task names to represent the response keys, so name cues were compatible with the response representation and mapping cues were incompatible with it. This allows us to test the compatibility account of the difference between name task and same cue RTs. If the difference is entirely due to compatibility, then name task RTs should be faster than same cue RTs only for the compatible name cues. Name task RTs should be slower than same cue RTs for the incompatible mapping cues. These predictions assume that neither name cues nor mapping cues are compatible with the "same" and "different" responses required for the same cue condition.

The mean cue RTs, plotted as a function of cue task and cue type in Figure 5, are not consistent with the compatibility account. Fisher's LSD test $(p<.05)$ showed that cue RTs to name cues were significantly faster in the name task condition than in the same cue condition, and cue RTs to mapping cues were significantly faster in the name task condition than in the same cue condition. Cue RTs to mapping cues in the name task condition (putatively incompatible responses) were faster than cue RTs to name cues in the same cue condition (putatively neutral re-

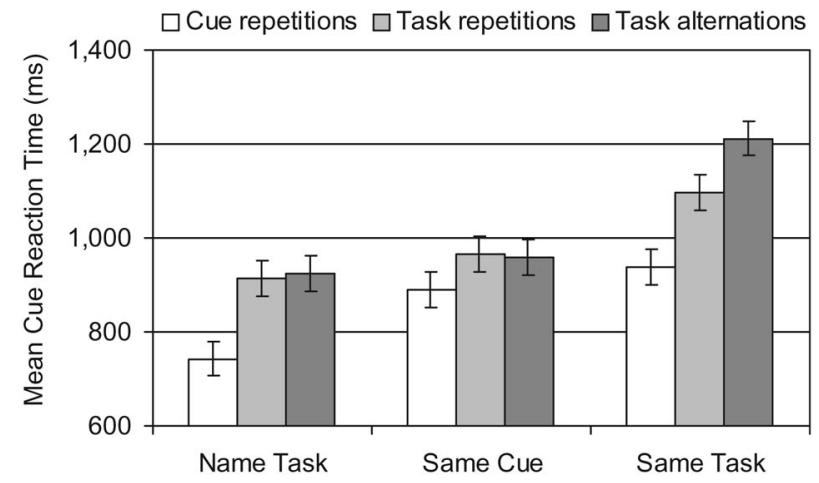

Figure 4. Mean reaction time to the cue in the name task, same cue, and same task conditions as a function of transition. The error bars are $95 \%$ confidence intervals constructed from Fisher's least significant difference, which was calculated from the interaction between cue task and transition.

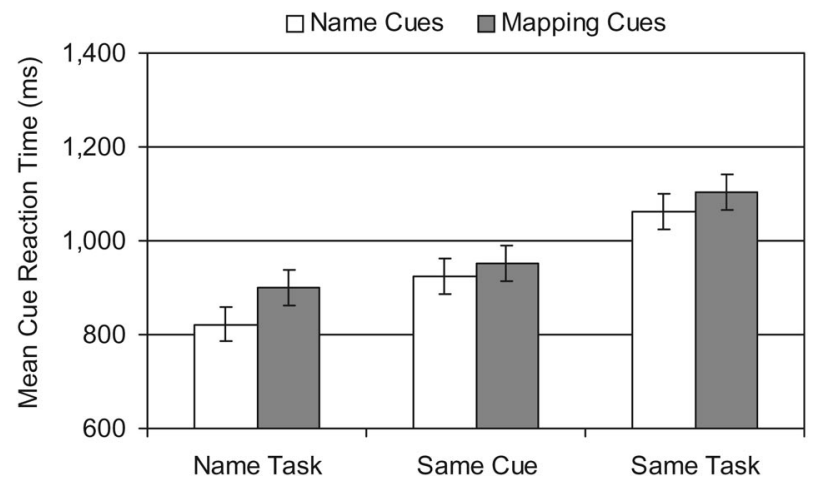

Figure 5. Mean reaction time to the cue in the name task, same cue, and same task conditions as a function of cue type. The error bars are $95 \%$ confidence intervals constructed from Fisher's least significant difference, which was calculated from the interaction between cue task and cue type.

sponses), but the difference was not significant by Fisher's LSD test. The critical point is that none of the comparisons shows differences consistent with the prediction we drew from Monsell and Mizon's (2006) sequential cue comparison strategy; name task RT was never slower than same cue RT, even when differential compatibility was taken into account.

Name-cue RTs were faster than mapping-cue RTs for each cue task, so the difference between cue types in the name task condition cannot be due entirely to cue-response compatibility. Name cues may have been easier to encode than mapping cues. However, the difference between name cues and mapping cues was greater for the name task condition ( $77 \mathrm{~ms}$ ) than for the same cue condition $(30 \mathrm{~ms})$ and the same task condition $(42 \mathrm{~ms})$, and a contrast comparing the difference in the name task condition with the average difference in the same cue and same task conditions was significant, $F(1,58)=5.00, p<.05, M S E=10,165.77$. This suggests there was a compatibility effect in the name task condition on top of a difference due to ease of encoding.

The comparison between the same task and name task conditions bears on the plausibility of our compound retrieval cue strategy and priming model. Averaged over transition and cue type, cue RT was significantly faster in the name task condition ( $M=860 \mathrm{~ms})$, which requires the essential computations in our

\footnotetext{
5 The Post-it notes that reminded subjects of the mapping of cues and tasks to responses should not have biased them to represent the cue responses as task names or mapping rules. All four cues were written on the Post-it reminder; that is, the Post-it depicted "Odd-Even (Parity)" on the left and "High-Low (Magnitude)" on the right.

${ }^{6}$ Arrington, Logan, and Schneider (in press) conducted an experiment that was the same as the name task condition, except that subjects responded vocally. Half of the subjects were required to respond with the task name ("magnitude" and "parity") and half were required to respond with the mapping ("high-low" and "odd-even"). For the former subjects, name cues were compatible with the required response and mapping cues were incompatible; for the latter subjects, mapping cues were compatible and name cues were incompatible. Averaged across groups and transitions, subjects were $172 \mathrm{~ms}$ faster to name compatible cues than to name incompatible ones. The 77-ms difference in the present name task condition was substantially smaller, consistent with our suggestion that keypress responses diminish cue compatibility effects.
} 
compound retrieval cue strategy, than in the same task condition ( $M=1,083 \mathrm{~ms}$ ), which requires the essential computations in the sequential task comparison strategy in the reconfiguration interpretation of switch costs, $F(1,58)=25.65, p<.01, M S E=$ 173,963.34. Subjects could gain more than $200 \mathrm{~ms}$ of processing time with our strategy, which is good reason for them to adopt it.

Target RT. Mean RTs and accuracy of target responses are presented in Table 3 as a function of cue task, transition, and cue type. Mean RTs are plotted as a function of cue task and transition in Figure 6. A 3 (cue task) $\times 3$ (transition) $\times 2$ (cue type) ANOVA on the mean RTs yielded significant main effects of cue task, $F(2$, $58)=8.62, p<.01, M S E=511,834.24$, and transition, $F(2$, $58)=144.10, p<.01, M S E=25,801.51$, and a significant interaction between cue task and transition, $F(4,116)=11.19$, $p<.01, M S E=20,772.26$. A 3 (cue task) $\times 3$ (transition) $\times 2$ (cue type) ANOVA on the percentages of correct responses yielded only a significant main effect of transition, $F(2,58)=$ 7.52, $p<.01$, MSE $=24.29$.

The most important results theoretically are the effects of cue task on target RT. Fast target RTs following a given cue task would suggest that that cue task is a natural component of the processing subjects normally engage in while performing explicitly cued task switching. The data are clear: Target RT in the name task condition ( $M=1,736 \mathrm{~ms}$ ) was significantly faster than target $\mathrm{RT}$ in the same cue condition $(M=1,930 \mathrm{~ms}), F(1,58)=6.57$, $p<.05, M S E=511,834.24$, and the same task condition $(M=$ $2,046 \mathrm{~ms}), F(1,58)=16.90, p<.01, M S E=511,834.24$. These data suggest that naming the task associated with the current cue is more natural than comparing the current cue or task to the previous one, consistent with our priming model.

Target RT was rather long in all conditions (cf. Logan \& Bundesen, 2003), suggesting that the requirement to respond to the cue disrupted target responses in all conditions, though perhaps least in the name task condition. Target RTs may have been prolonged partly because the interval between the response to the cue and the onset of the cue-plus-target display was very briefonly $100 \mathrm{~ms}$. The brief delay may have produced some refractory effects on target RTs (Pashler, 1994). The important question is whether the prolongation of target RTs compromised the interpretation of the transition effects. The data suggest it did not, at least

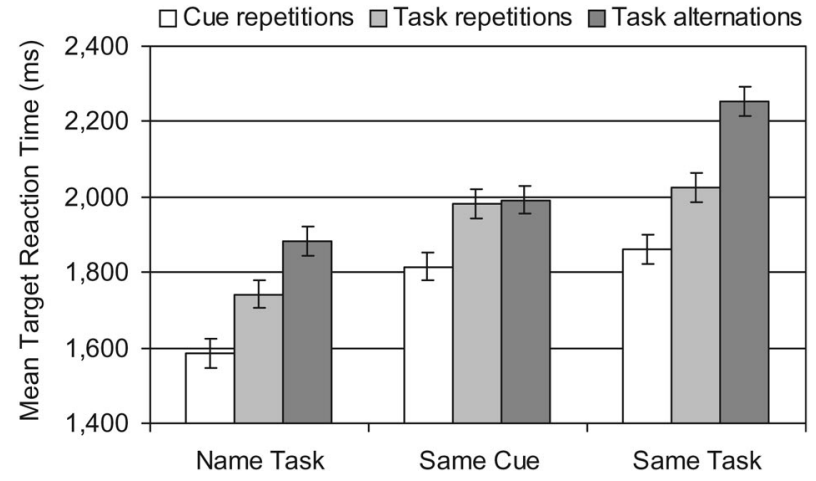

Figure 6. Mean reaction time to the target in the name task, same cue, and same task conditions as a function of transition. The error bars are $95 \%$ confidence intervals constructed from Fisher's least significant difference, which was calculated from the interaction between cue task and transition. in the name task and same cue conditions. The true switch costs in these conditions were $140 \mathrm{~ms}$ and $10 \mathrm{~ms}$, respectively. These values are within the range of switch costs observed in previous experiments (see TA - TR in Figure 3). However, the 229-ms true switch cost in the same task condition was larger than any observed in our previous experiments, suggesting that indicating whether the current task was the same as the previous one may have disrupted normal processing.

The observation of true switch costs in the target RTs is important theoretically. It falsifies our priming model's assumption that all of the transition effects in the explicit task-cuing procedure are due to cue encoding (e.g., benefits from repetition, benefits from semantic or associative priming; see Schneider \& Logan, 2005). However, two factors mitigate this falsification. First, there were significant differences between cue repetitions and task repetitions in the target RTs $(157,167$, and $162 \mathrm{~ms}$ for the name task, same cue, and same task conditions, respectively). This suggests that cue encoding may not have been complete at the time the cue response occurred, so that some cue encoding effects "spilled over" into the target RT interval. That is, cue encoding may involve more than simply naming the task indicated by the cue, comparing the cue with the previous cue, or comparing the cued task with the previous task. However, Arrington et al. (in press) found significant true switch costs in target RTs when cue encoding effects were almost entirely contained in cue RTs, suggesting that the switch costs in the present target RTs cannot be due entirely to spill-over effects from cue encoding. Further research will be required to settle this question.

Second, although we make the strong claim with our priming model that true switch costs do not reflect endogenous reconfiguration, there is no direct evidence indicating that the true switch costs in the present experiment and the experiments of Arrington et al. (in press) reflect the duration of an endogenous reconfiguration process. They could reflect interference from the previous task set (Allport et al., 1994) or interference from competing responses associated with the current target (Waszak, Hommel, \& Allport, 2003; Wylie \& Allport, 2000). In previous work, we have accounted for effects like these with a shift in the $R T_{\text {Base }}$ parameter for task alternations, relative to cue repetitions and task repetitions (Arrington \& Logan, 2004a; Logan \& Bundesen, 2004). We have not modeled these interference processes, but we have modeled cue-target congruency effects that produce changes in $R T_{\text {Base }}$ (Schneider \& Logan, 2005). Future research will be required to determine whether the true switch costs in the target RTs reflect endogenous reconfiguration or the interference effects discovered by Allport and colleagues.

\section{Summary and Implications}

The cue RTs rule out Monsell and Mizon's (2006) sequential cue comparison strategy by falsifying its assumption that information about differences between the current cue and the previous one is available before information about the identity of the current cue. Same-cue cue RTs were slower than name-task cue RTs, which is opposite to this prediction. Moreover, the cue RTs also suggest that the sequential task comparison strategy that underlies the reconfiguration interpretation of switch costs in the explicit task-cuing procedure is less plausible than the compound retrieval cue strategy in our priming model. Same-task cue RTs were 
significantly slower than name-task cue RTs, suggesting that subjects could perform faster with our strategy than with the sequential task comparison strategy. The target RTs corroborate these conclusions, showing that naming tasks speeds target processing as well as cue encoding. Our compound retrieval cue strategy leads to faster processing than the alternatives, so it would make sense for subjects to choose it rather than the alternatives to comply with the instructions to respond as quickly as they can. The target RTs show true switch costs in the name task condition, which are inconsistent with our claim that all transition effects reflect priming of cue encoding. However, these true switch costs do not necessarily reflect endogenous reconfiguration. They could reflect interference from previous task sets and interference from associations between targets and competing responses, as documented by Allport and colleagues (Allport et al., 1994; Waszak et al., 2003; Wylie \& Allport, 2000).

The cue RTs measure cue identification, cue comparison, and task comparison explicitly, requiring subjects to make an overt response indicating their interpretation of the stimuli. We believe that our explicit tasks provide fair tests of Monsell and Mizon's (2006) sequential cue comparison strategy and the sequential task comparison strategy associated with the reconfiguration view of task switching. Monsell and Mizon explicitly assume that "task set preparation ... is a voluntary process" (p. 500) and they describe sequential cue comparison as "a tempting strategy" (p. 500). Surely, voluntary strategies are explicit. Monsell and Mizon describe preparation and reconfiguration in language that implies intentionality, with "participants" as active agents: "participants ... engage in some sort of preparation," "participants ... move their control state," and "participants might probability match" (p. 511). Surely, intentional agents have explicit knowledge of their deliberate actions (Dennett, 1987). The explicit knowledge of a cue that is used to decide whether to reconfigure could also be used to make the explicit response to the cue that we required in our experiment.

However, Monsell and Mizon (2006) do not say directly whether subjects have explicit knowledge of the current cue and the relations between it and previous cues. It may be possible to salvage their position by assuming that subjects' knowledge of the cues is implicit and this implicit knowledge has a different time course than the explicit knowledge we have measured. We believe this interpretation would be hard to defend for two reasons. First, Monsell and Mizon's view of reconfiguration is unlikely to rely on implicit processes in this sense. They claim that reconfiguration might include "orienting attention toward another location or to different perceptual or conceptual attributes of the stimuli; activating or suppressing particular stimulus-response translation 'rules' or computational procedures; readying a new response set; adjusting decision or response criteria; and so forth" (p. 493). This view assumes that reconfiguration operations require access to many different processes or modules. However, many researchers assume that implicit effects are localized within a single process or a single module (Ratcliff \& McKoon, 1997; Roediger, 1990; Schacter, 1994). Second, there is no guarantee that the time course of implicit knowledge of cues and the relations between them would support Monsell and Mizon's predictions. Implicit effects are not always different from explicit effects. Associations are as common as dissociations (e.g., Speelman \& Kirsner, 2005). The time course of implicit knowledge would have to be measured somehow, and the implicit detection of a difference between successive cues would have to occur well before implicit identification of the cue in order to allow the number of required task switches.

Whether Monsell and Mizon (2006) assumed their strategies were implicit or explicit, they chose to defend the position that Logan and Bundesen (2003) challenged, and that position assumed deliberate actions by an intentional agent with explicit knowledge. The title of that article asked "Is there an endogenous act of control in the explicit task-cuing procedure?" Models 1 and $2+1$ were attempts to formalize the sequential task comparison strategy in reconfiguration approaches to task switching. We believe that the explicit measures in the present article provide appropriate tests of the position we challenged.

\section{Monsell and Mizon's (2006) Recipe for Measuring Task- Set Reconfiguration}

Monsell and Mizon (2006) ended their article with a recipe for measuring task-set reconfiguration. We believe it would be more appropriate to call it a recipe for observing a reduction in true switch cost with SOA, because that is what it addresses and we have shown that our priming model predicts this reduction without assuming reconfiguration. However, we think there are problems with their recipe even if it is used only for observing reductions in true switch cost with SOA.

"Use at least two cues per task" (p. 514). We agree with this recommendation because it is essential to separate cue encoding benefits from true switch costs. However, using two cues per task may be necessary, but it is not sufficient. First, if the cues assigned to each task are related semantically or associatively, it is possible that true switch costs will occur because of priming rather than endogenous reconfiguration (see Equations 5 and 6). Second, using two cues per task does not allow one to completely deconfound cue transitions from task transitions because it is not possible to have a task alternation trial in which the cue repeats, and this methodological limitation could influence how effects are interpreted (Forstmann, Brass, \& Koch, in press).

"Keep [response-to-stimulus interval] constant (to unconfound active preparation and decay of carryover of task set) while varying [cue-to-stimulus interval]" ( $p$. 514). We believe this is not necessary. We have observed significant reductions in true switch costs with SOA (i.e., cue-to-stimulus interval) in experiments in which response-to-stimulus interval is not constant (Logan \& Schneider, 2006b; Schneider \& Logan, 2006). Moreover, there have been many demonstrations that the effects of SOA between cues and targets are separate from the effects of the interval between successive targets (Arrington \& Logan, 2004a; Logan \& Bundesen, 2003; Logan \& Schneider, 2006b; Logan \& Zbrodoff, 1982; Mayr \& Kliegl, 2000, 2003; Meiran, 1996; Meiran, Chorev, \& Sapir, 2000). Meiran et al. (2000) have shown that carry-over effects largely dissipate within $1,000 \mathrm{~ms}$ of the response on the previous trial, so experiments with response-to-cue intervals of $1,000 \mathrm{~ms}$ or more should not be compromised by carry-over effects. We believe this issue has been laid to rest by an ample amount of research, so it need not be a concern in future studies.

Monsell and Mizon's (2006) recommendation is based on the idea that it is important to make target occurrence predictable (pp. 505-506). Their recommendation seems to imply that it is not 
important to make cue occurrence predictable, as it generally is in our experiments. This idea appears to reflect a belief that cue processing is not important in the explicit task-cuing procedure-a belief that has been challenged by much of our research.

"Keep the probability of a task switch relatively low" ( $p$. 514). We believe this is problematic. Manipulating the probability of a task switch necessarily varies other aspects of the procedure, like the probability of a task switch given a cue switch. Most important from our perspective, it also varies the probability that one cue will follow another (Table 1) and it varies the probability with which longer sequences of cues can occur (see Gotler et al., 2003; Heuer et al., 2001; Koch, 2001). Our modeling of Schneider and Logan's (2006) data and Monsell and Mizon's (2006) Experiment 6 shows that transition probability can affect cue encoding independent of reconfiguration. The estimates of cue encoding times were faster for frequent transitions than for infrequent transitions for cue repetitions, task repetitions, and task alternations, and the proportional speed-up was the same for all transitions (Table 2). More research will be necessary to sort out all of the factors that are affected by manipulating the probability of a task switch, to determine which, if any, reflect endogenous reconfiguration.

Monsell and Mizon's (2006) recommendation is based on the idea that subjects compare successive cues or tasks and switch when they change. The cue RTs and target RTs from our experiment suggest that subjects are unlikely to use these sequential cue- and task-comparison strategies. The comparisons take longer than simply encoding the cue and they result in longer target RTs. Subjects who are interested in minimizing processing time would be better off adopting our compound retrieval cue strategy.

"Use cues that are easy to interpret (lest interpreting the cue should constitute a separate task)” (p. 515). Monsell and Mizon provide no empirical or theoretical basis for this recommendation. Our data suggest that it is unwarranted. In our experiment, cue processing did constitute a separate task, and we observed significant true switch costs in target RTs after two of the three tasks subjects performed on the cue (see Figure 6). Large true switch costs were observed in target RTs in the same task condition, which produced the longest cue RTs and so was the most difficult task performed on the cues.

Several studies have shown that much can be learned by comparing arbitrary and meaningful cues (Arbuthnott \& Woodward, 2002; Logan \& Bundesen, 2004; Logan \& Schneider, 2006a; Mayr \& Kliegl, 2000; Miyake et al., 2004). True switch costs are generally larger with arbitrary, hard-to-interpret cues (see Figure 3). We believe it will be more productive to explore the reasons why some cues are easier to interpret than others and discover the effects that ease of cue use has on taskswitching performance than to follow Monsell and Mizon's (2006) prescription.

"Apply incentives and give instructions that will motivate participants to use the information in the cue to prepare" ( $p$. 515). It is hard to argue against this recommendation because following it would lead to better data in almost any experiment. However, it is not clear that it will increase the likelihood of observing endogenous reconfiguration more than other effects (see Nieuwenhuis \& Monsell, 2002).

\section{An Alternative Recipe for Measuring Endogenous Reconfiguration}

The allure of task-switching procedures is that they promise a measure of endogenous reconfiguration that will allow us to capture the elusive homunculus responsible for executive control and study it in the laboratory. We are victims of this allure ourselves, and we offer our own recipe for measuring endogenous reconfiguration:

Use procedures that are likely to require endogenous processing. The explicit task-cuing procedure provides enough information on each trial to uniquely specify the correct response. The procedure is a simple conditional discrimination that a trained monkey could learn (Stoet \& Snyder, 2003). In our view, nothing needs to be reconfigured. Task-switching procedures that require an endogenous act on the part of the subject are more likely to reveal endogenous processing. The voluntary task-switching procedure (Arrington \& Logan, 2004b, 2005) and the task span procedure (Logan, 2004) are examples of task-switching procedures that require endogenous acts from the subject. Other procedures may also require endogenous acts.

Include manipulations that are diagnostic of different configurations of the cognitive system. We have shown that reconfiguration and priming can both produce a reduction in true switch cost with SOA, so that effect is not diagnostic of reconfiguration. Some other criterion must be used to conclude that reconfiguration has occurred. We suggest including manipulations in an experiment that are diagnostic of different configurations of the cognitive system (see Schneider \& Logan, in press). If different diagnostic effects can be linked to different task sets, then it is more likely that task switching involves some form of reconfiguration. A corollary to this recommendation is that researchers should avoid using tasks that can be solved by simple memory retrieval. Switching between different retrieval cues is unlikely to involve the kind of reconfiguration that researchers seek (Schneider \& Logan, 2005).

Use a theory to guide the search for endogenous processing. Cognitive psychologists define processes in terms of the inputs they take and the outputs they produce. Most theoretical processes are grounded in the environment, taking observable stimuli as input or producing observable responses as output. Executive control processes are hard to define because their inputs are states of other processes and their outputs are changes in states of other processes. In order to talk meaningfully about executive control, the control processes must be grounded in a strong theory of the subordinate processes that defines their states rigorously and, consequently, defines the inputs and outputs of the executive system. Logan and Gordon's (2001) ECTVA is an example of this approach, grounding its theory of executive processing in Bundesen's (1990) theory of visual attention (TVA), which itself has been grounded in single-cell neurophysiology (Bundesen, Habekost, \& Kyllingsbaek, 2005). Bundesen's theory has specific control parameters that the executive can adjust to program it to select different objects and categorize them in different ways. For example, the theory says that spatial attention is directed by manipulating priority parameters that control the objects that TVA selects. Logan's (2005) analysis of shifting spatial attention and Logan and Gordon's (2001) analysis of switching between tasks in dual-task conditions exploited this feature of TVA. 
Of course, ECTVA is not the only way a theory of executive processing can be grounded in a theory of subordinate processing. Gilbert and Shallice (2002) grounded their theory of task switching in Stroop situations in Cohen, Dunbar, and McClelland's (1990) parallel distributed processing model of the Stroop task. Sohn and Anderson (2001) and Altmann (2002; Altmann \& Gray, 2002) grounded their theories of task switching in Anderson's (1993) adaptive control of thought - rational model of cognition. Kieras, Meyer, Ballas, and Lauber (2000) grounded their work on task switching in Meyer and Kieras's (1997) executive processinteractive control theory. Each of these approaches provides a principled way of determining what is subordinate processing and what is executive processing, which is an essential step in measuring the endogenous control processes we all seek.

\section{Searching for the Homunculus in the Explicit Task-Cuing Procedure}

It is important to be clear about what we are claiming and what we are not claiming. We are claiming that switch costs in the explicit task-cuing procedure-even true switch costs measured with two cues per task-do not necessarily reflect endogenous control processes. We have shown that a single task set is sufficient to account for performance in that procedure, and that differences between cue repetitions, task repetitions, and task alternations can be understood in terms of repetition priming and semantic or associative priming without invoking endogenous control processes. However, our claim that switch costs do not reflect endogenous control does not imply that the explicit taskcuing procedure does not require endogenous control. We believe that it does. Subjects perform the task voluntarily, giving informed consent and being fully aware of their right to terminate the experiment at any moment. Each trial is an act of will. The single task set required for performance involves deliberate perceptual and motor adjustments-subjects must decide to look at the screen and decide to rest their fingers on the appropriate response keys throughout the experiment. Moreover, subjects may adjust their performance between trials throughout the experiment to maximize speed and accuracy, though we have not looked for these adjustments in our data. All of these things are hallmarks of endogenous processing, so surely the homunculus is present in our experiments. We are only suggesting that it is not differentially present for task repetitions and task alternations, so researchers may have to look elsewhere when searching for indices of executive control.

\section{References}

Allport, A., Styles, E. A., \& Hsieh, S. (1994). Shifting intentional set: Exploring the dynamic control of tasks. In C. Umiltà \& M. Moscovitch (Eds.), Attention and performance XV (pp. 421-452). Cambridge, MA: MIT Press.

Altmann, E. M. (2002). Functional decay of memory for tasks. Psychological Research, 66, 287-297.

Altmann, E. M. (2004). The preparation effect in task switching: Carryover of SOA. Memory \& Cognition, 32, 153-163.

Altmann, E. M., \& Gray, W. D. (2002). Forgetting to remember: The functional relationship of decay and interference. Psychological Science, $13,27-33$.

Anderson, J. R. (1993). Rules of the mind. Hillsdale, NJ: Erlbaum.
Arbuthnott, K. D., \& Woodward, T. S. (2002). The influence of cue-task association and location on switch cost and alternating switch cost. Canadian Journal of Experimental Psychology, 56, 18-29.

Arrington, C. M., \& Logan, G. D. (2004a). Episodic and semantic components of the compound-stimulus strategy in the explicit task-cuing procedure. Memory \& Cognition, 32, 965-978.

Arrington, C. M., \& Logan, G. D. (2004b). The cost of a voluntary task switch. Psychological Science, 15, 610-615.

Arrington, C. M., \& Logan, G. D. (2005). Voluntary task switching: Chasing the elusive homunculus. Journal of Experimental Psychology: Learning, Memory, and Cognition, 31, 683-702.

Arrington, C. M., Logan, G. D., \& Schneider, D. W. (in press). Separating cue encoding from target processing in the explicit task-cuing procedure: Are there "true" task switch effects? Journal of Experimental Psychology: Learning, Memory, and Cognition.

Bundesen, C. (1990). A theory of visual attention. Psychological Review, 97, 523-547.

Bundesen, C., Habekost, T., \& Kyllingsbaek, S. (2005). A neural theory of visual attention: Bridging cognition and neurophysiology. Psychological Review, 112, 291-328.

Cohen, J. D., Dunbar, K., \& McClelland, J. L. (1990). On the control of automatic processes: A parallel distributed processing account of the Stroop effect. Psychological Review, 97, 332-361.

Dennett, D. C. (1987). The intentional stance. Cambridge, MA: MIT Press.

Forstmann, B. U., Brass, M., \& Koch, I. (in press). Methodological and empirical issues when dissociating cue-related from task-related processes in the explicit task-cuing procedure. Psychological Research.

Gilbert, S. J., \& Shallice, T. (2002). Task switching: A PDP model. Cognitive Psychology, 44, 297-337.

Gotler, A., Meiran, N., \& Tzelgov, J. (2003). Nonintentional task set activation: Evidence from implicit task sequence learning. Psychonomic Bulletin \& Review, 10, 890-896.

Heuer, H., Schmidtke, V., \& Kleinsorge, T. (2001). Implicit learning of sequences of tasks. Journal of Experimental Psychology: Learning, Memory, and Cognition, 27, 967-983.

Hyman, R. (1953). Stimulus information as a determinant of reaction time. Journal of Experimental Psychology, 45, 188-196.

Jersild, A. T. (1927). Mental set and shift. Archives of Psychology, 14 (Whole No. 89).

Kieras, D. E., Meyer, D. E., Ballas, J. A., \& Lauber, E. J. (2000). Modern computational perspectives on executive mental processes and cognitive control: Where to from here? In S. Monsell \& J. Driver (Eds.), Control of cognitive processes: Attention and performance XVIII (pp. 681-712). Cambridge, MA: MIT Press.

Koch, I. (2001). Automatic and intentional activation of task sets. Journal of Experimental Psychology: Learning, Memory, and Cognition, 27, $1474-1486$

Laming, D. R. J. (1968). Information theory of choice-reaction times. New York: Academic Press.

Logan, G. D. (1985). Executive control of thought and action. Acta Psychologica, 60, 193-210.

Logan, G. D. (2002). An instance theory of attention and memory. Psychological Review, 109, 376-400.

Logan, G. D. (2003). Executive control of thought and action: In search of the wild homunculus. Current Directions in Psychological Science, 12, $45-48$.

Logan, G. D. (2004). Working memory, task switching, and executive control in the task span procedure. Journal of Experimental Psychology: General, 133, 218-236.

Logan, G. D. (2005). The time it takes to switch attention. Psychonomic Bulletin \& Review, 12, 647-653.

Logan, G. D., \& Bundesen, C. (2003). Clever homunculus: Is there an endogenous act of control in the explicit task-cuing procedure? Journal 
of Experimental Psychology: Human Perception and Performance, 29, $575-599$.

Logan, G. D., \& Bundesen, C. (2004). Very clever homunculus: Compound stimulus strategies for the explicit task-cuing procedure. Psychonomic Bulletin \& Review, 11, 832-840.

Logan, G. D., \& Gordon, R. D. (2001). Executive control of visual attention in dual-task situations. Psychological Review, 108, 393-434.

Logan, G. D., \& Schneider, D. W. (2006a). Interpreting instructional cues in task switching procedures: The role of mediator retrieval. Journal of Experimental Psychology: Learning, Memory, and Cognition, 32, 347363.

Logan, G. D., \& Schneider, D. W. (2006b). Priming or executive control? Associative priming of cue encoding increases "switch costs" in the explicit task-cuing procedure. Memory \& Cognition, 34, 1250-1259.

Logan, G. D., \& Zbrodoff, N. J. (1982). Constraints on strategy construction in a speeded discrimination task. Journal of Experimental Psychology: Human Perception and Performance, 8, 502-520.

Mayr, U., \& Kliegl, R. (2000). Task-set switching and long-term memory retrieval. Journal of Experimental Psychology: Learning, Memory, and Cognition, 26, 1124-1140.

Mayr, U., \& Kliegl, R. (2003). Differential effects of cue changes and task changes on task-set selection costs. Journal of Experimental Psychology: Learning, Memory, and Cognition, 29, 362-372.

Medin, D. L., \& Shaffer, M. M. (1978). Context theory of classification. Psychological Review, 85, 207-238.

Meiran, N. (1996). Reconfiguration of processing mode prior to task performance. Journal of Experimental Psychology: Learning, Memory, and Cognition, 22, 1423-1442.

Meiran, N. (2000). Modeling cognitive control in task-switching. Psychological Research, 63, 234-249.

Meiran, N., Chorev, Z., \& Sapir, A. (2000). Component processes in task switching. Cognitive Psychology, 41, 211-253.

Meyer, D. E., \& Kieras, D. E. (1997). A computational theory of executive cognitive processes and multiple-task performance: Part 1. Basic mechanisms. Psychological Review, 104, 3-65.

Miller, E. K., \& Cohen, J. D. (2001). An integrative theory of prefrontal cortex function. Annual Review of Neuroscience, 24, 167-202.

Miyake, A., Emerson, M. J., Padilla, F., \& Ahn, J. (2004). Inner speech as a retrieval aid for task goals: The effects of cue type and articulatory suppression in the random task cuing paradigm. Acta Psychologica, 115, 123-142.

Monsell, S. (1996). Control of mental processes. In V. Bruce (Ed.), Unsolved mysteries of the mind (pp. 93-148). Hove, England: Erlbaum.

Monsell, S. (2003). Task switching. Trends in Cognitive Sciences, 7 , $134-140$.

Monsell, S., \& Mizon, G. A. (2006). Can the task-cuing paradigm measure an endogenous task-set reconfiguration process? Journal of Experimental Psychology: Human Perception and Performance, 32, 493-516.

Neely, J. H. (1977). Semantic priming and retrieval from lexical memory: Roles of inhibitionless spreading activation and limited-capacity attention. Journal of Experimental Psychology: General, 106, 226-254.
Nelson, D. L., McEvoy, C. L., \& Schreiber, T. A. (1999). The University of South Florida word association, rhyme, and fragment judgment norms. Retrieved February 5, 2004, from http://w3.usf.edu/FreeAssociation/

Nieuwenhuis, S., \& Monsell, S. (2002). Residual costs in task switching: Testing the failure-to-engage hypothesis. Psychonomic Bulletin \& Review, 9, 86-92.

Nosofsky, R. M. (1984). Choice, similarity, and the context theory of classification. Journal of Experimental Psychology: Human Perception and Performance, 10, 104-114.

Nosofsky, R. M., \& Palmeri, T. J. (1997). An exemplar-based random walk model of speeded classification. Psychological Review, 104, 266-300.

Pashler, H. (1994). Dual-task interference in simple tasks: Data and theory. Psychological Bulletin, 116, 220-244.

Ratcliff, R., \& McKoon, G. (1987). A counter model for implicit priming in perceptual word identification. Psychological Review, 104, 319-343.

Roediger, H. L., III. (1990). Implicit memory: Retention without remembering. American Psychologist, 45, 1043-1056.

Rogers, R. D., \& Monsell, S. (1995). Costs of a predictable switch between simple cognitive tasks. Journal of Experimental Psychology: General, 124, 207-231.

Rubinstein, J. S., Meyer, D. E., \& Evans, J. E. (2001). Executive control of cognitive processes in task switching. Journal of Experimental Psychology: Human Perception and Performance, 27, 763-797.

Schacter, D. L. (1994). Priming and multiple memory systems: Perceptual mechanisms of implicit memory. In D. L. Schacter \& E. Tulving (Eds.), Memory systems 1994 (pp. 233-238). Cambridge, MA: MIT Press.

Schneider, D. W., \& Logan, G. D. (2005). Modeling task switching without switching tasks: A short-term priming account of explicitly cued performance. Journal of Experimental Psychology: General, 134, 343-367.

Schneider, D. W., \& Logan, G. D. (2006). Priming cue encoding by manipulating transition frequency in explicitly cued task switching. Psychonomic Bulletin \& Review, 13, 145-151.

Schneider, D. W., \& Logan, G. D. (in press). Defining task-set reconfiguration: The case of reference point switching. Psychonomic Bulletin \& Review.

Sohn, M-H., \& Anderson, J. R. (2001). Task preparation and task repetition: Two-component model of task switching. Journal of Experimental Psychology: General, 130, 764-778.

Speelman, C. P., \& Kirsner, K. (2005). Beyond the learning curve: The construction of mind. Oxford, England: Oxford University Press.

Stoet, G., \& Snyder, L. H. (2003). Task preparation in macaque monkeys (Macaca mulatta). Animal Cognition, 6, 121-130.

Waszak, F., Hommel, B., \& Allport, A. (2003). Task-switching and longterm priming: Role of episodic stimulus-task bindings in task-shift costs. Cognitive Psychology, 46, 361-413.

Wylie, G., \& Allport, A. (2000). Task switching and the measurement of "switch costs." Psychological Research, 63, 212-233.

Received January 25, 2006 Revision received October 4, 2006 Accepted October 30, 2006 